\title{
Melting and freezing under Antarctic ice shelves from a combination of ice-sheet modelling and observations
}

\author{
JORGE BERNALES, ${ }^{1,2}$ IRINA ROGOZHINA, ${ }^{3,1}$ MAIK THOMAS ${ }^{1,2}$ \\ ${ }^{1}$ GFZ German Research Centre for Geosciences, Section 1.3: Earth System Modelling, Potsdam, Germany \\ ${ }^{2}$ Institute of Meteorology, Free University Berlin, Berlin, Germany \\ ${ }^{3}$ MARUM Centre for Marine Environmental Sciences, University of Bremen, Bremen, Germany \\ Correspondence: Jorge Bernales <bernales@gfz-potsdam.de>
}

\begin{abstract}
Ice-shelf basal melting is the largest contributor to the negative mass balance of the Antarctic ice sheet. However, current implementations of ice/ocean interactions in ice-sheet models disagree with the distribution of sub-shelf melt and freezing rates revealed by recent observational studies. Here we present a novel combination of a continental-scale ice flow model and a calibration technique to derive the spatial distribution of basal melting and freezing rates for the whole Antarctic ice-shelf system. The modelled ice-sheet equilibrium state is evaluated against topographic and velocity observations. Our high-resolution (10-km spacing) simulation predicts an equilibrium ice-shelf basal mass balance of $-1648.7 \mathrm{Gt} \mathrm{a}^{-1}$ that increases to $-1917.0 \mathrm{Gt} \mathrm{a}^{-1}$ when the observed ice-shelf thinning rates are taken into account. Our estimates reproduce the complexity of the basal mass balance of Antarctic ice shelves, providing a reference for parameterisations of sub-shelf ocean/ice interactions in continental ice-sheet models. We perform a sensitivity analysis to assess the effects of variations in the model set-up, showing that the retrieved estimates of basal melting and freezing rates are largely insensitive to changes in the internal model parameters, but respond strongly to a reduction of model resolution and the uncertainty in the input datasets.
\end{abstract}

KEYWORDS: Antarctic glaciology, basal melt, ice/ocean interactions, ice-sheet modelling, ice shelves

\section{INTRODUCTION}

Ice shelves are floating ice masses connected to and nourished by land-based ice. They are thought to exert an important control on the dynamics of the grounded ice-sheet sectors (Rignot and others, 2004; Dupont and Alley, 2005; Rott and others, 2011; Gudmundsson, 2013), buttressing and buffering the ice flux where it reaches the ocean. Thus, ice shelf thinning and removal holds an indirect, albeit significant potential for a contribution to sea-level variations. Recent studies have shown that changes in the ocean thermal state play a critical role in ice-shelf thinning and a subsequent loss of buttressing (e.g., Pritchard and others, 2012). Present-day observations suggest that over a half of the Antarctic mass loss is due to sub-shelf basal melting (Depoorter and others, 2013; Rignot and others, 2013), with melting rates ranging from a few centimeters to tens of meters per year, and values near grounding lines exceeding area-averaged rates by one to two orders of magnitude (Rignot and others, 2002). Since basal melt rates are likely to increase in the future due to increasing ocean temperatures (e.g. Gillett and others, 2011; Yin and others, 2011; Hellmer and others, 2012), a better understanding of their magnitudes and spatial distribution is a crucial requirement for reliable projections of the ice-sheet evolution and sealevel rise (Joughin and others, 2012).

Net melt rates under ice shelves have been previously estimated using different techniques based on surrounding oceanographic data (Gammelsrod and others, 1994; Foldvik and others, 2001; Jenkins and Jacobs, 2008; Jacobs and others, 2011), local glaciological observations (Doake, 1984; Jacobs and others, 1992; Rignot and others, 2002;
Joughin and Padman, 2003; Wen and others, 2010) and satellite data (Depoorter and others, 2013; Rignot and others, 2013). Numerical ocean modelling has provided high-resolution reconstructions of basal melt rates under a number of individual ice shelves (Gerdes and others, 1999; Jenkins and Holland, 2002; Holland and others, 2009, 2010; Hellmer and others, 2012; Padman and others, 2012; Schodlok and others, 2012) and total ice-shelf meltwater production estimates from circumpolar simulations (Hellmer, 2004; Timmermann and others, 2012). These studies have presented total ice-shelf basal mass balance (BMB) estimates ranging from $\sim-500$ to $\sim-1700 \mathrm{Gt} \mathrm{a}^{-1}$. Recent estimates based on satellite data (Depoorter and others, 2013; Rignot and others, 2013) have uncovered the spatial distribution of the melting and freezing zones for the entire Antarctic ice-shelf system. Although the total BMB estimates provided by these particular studies are comparable and within the above-mentioned range, they disagree in the contributions of individual ice-shelf sectors (Depoorter and others, 2013; Rignot and others, 2013).

Ice flow models require an accurate quantification of the ice-shelf $\mathrm{BMB}$ to reproduce the dynamics of ice when it is in contact with the ocean. Due to scarcity of wholeAntarctic BMB estimates in the past and high computational costs of coupled regional ocean-ice-sheet modelling experiments, stand-alone continental-scale ice models have so far mostly relied on simplified parameterisations to account for ice/ocean interactions. These approaches range from a prescription of a single-value (spatially uniform) basal melting rates over the entire domain (e.g. Bindschadler and others, 2013) to simplified parameterisations using homogeneous 
or modelled (extrapolated) ocean temperatures (e.g. Beckmann and Goosse, 2003; Holland and others, 2008), which are kept constant in space and time (e.g. Martin and others, 2011; de Boer and others, 2015). These parameterisations are commonly calibrated against the observed ice volumes and extents, and the resulting melting rates are not necessarily consistent with the oceanographic and glaciological BMB estimates. Furthermore, these parameterisations usually disregard sub-shelf freezing processes that have been shown by observational studies to occur under vast portions of the Antarctic ice shelves.

Here, we build upon the concepts used to interpret observations (Depoorter and others, 2013; Rignot and others, 2013) and implement a method combining stand-alone icesheet-shelf simulations and topographic data (Bernales and others, 2017) to quantify sub-shelf melting and freezing rates. With this novel approach, we derive total, sectorand ice shelf-specific BMB values that can be directly compared with previous glaciological and oceanographic estimates. Furthermore, the use of a numerical model allows us to explore the sensitivity of the results to changes in the model grid resolution, and uncertainties in the input data-sets and model parameters.

\section{METHODS}

\subsection{Ice-sheet-shelf model}

We use the ice-sheet-shelf model SICOPOLIS (SImulation COde for POLythermal ice sheets) version 3.2, revision 619 (Greve and Blatter, 2009; Sato and Greve, 2012). The model set-up closely follows that of Bernales and others (2017). The experiments described in this study use a onelayer enthalpy scheme recently implemented in the model (Greve and Blatter, 2016). Additional modifications to the model specifically for this study are presented below.

At its core, the model solves for the ice velocity using finite-difference implementations of the Shallow Ice and Shallow Shelf Approximations (SIA and SSA, respectively; e.g. Hutter, 1983; Morland, 1987). The SSA is used to compute ice velocities of ice shelves, which experience almost no friction at their interface with sea water, whereas the SIA is used across the grounded ice-sheet sectors, where the mechanical properties of the bedrock and crustal heat flow create a variety of friction conditions, ranging from nearly immobile ice masses frozen to bed to fast flowing ice streams sliding over water-saturated sediments. Since basal sliding is not accounted for in the SIA, ice flow models have traditionally implemented various empirical sliding laws as an additional boundary condition. Bueler and Brown (2009) proposed to use a modified SSA including basal drag (also known as the Shelfy Stream Approximation, SStA) as a sliding law, showing that this heuristic, 'hybrid' combination of the SIA and the SStA is able to reproduce most ice flow regimes. Bernales and others (2017) compared different implementations of this idea, and in this study we are using a modification of the approach proposed by Winkelmann and others (2011), as follows: first, the SIA velocities are computed while setting basal velocities to zero. Then, the SStA velocities are computed using a Weertmantype sliding law (see Bernales and others, 2017, Eqns (2)(6)) with a basal drag coefficient that has been calibrated to minimise the difference between the modelled and observed ice-thickness data (Pollard and DeConto, 2012; Bernales and others, 2017). Finally, both solutions are combined over the entire ice sheet using

$$
\mathbf{U}=(1-w) \cdot \mathbf{u}_{\text {sia }}+\mathbf{u}_{\text {ssta }}
$$

where $\mathbf{u}_{\text {sia }}$ and $\mathbf{u}_{\text {ssta }}$ are the SIA and SStA horizontal velocities, respectively, and $w$ is a weight computed following Bueler and Brown (2009):

$$
w\left(\left|\mathbf{u}_{\mathrm{ssta}}\right|\right)=\frac{2}{\pi} \arctan \left(\frac{\left|\mathbf{u}_{\mathrm{ssta}}\right|^{2}}{u_{\text {ref }}^{2}}\right),
$$

where $u_{\text {ref }}$ is a reference velocity, set to $30 \mathrm{~m} \mathrm{a}^{-1}$, following Bernales and others (2017). This particular scheme decreases the contribution of the SIA velocities in areas where high SStA velocities are detected. Such fast flowing areas are mostly located near ice-sheet margins, where ice streams operate and the assumptions behind the SIA are no longer valid. The hybrid scheme presented in this study reduces instabilities in these regions caused by artificially high SIA velocities, the absence of which is assumed but not assured by Winkelmann and others (2011). The resulting ice velocity is used to solve the evolution equations of the ice thickness and temperature (Greve and Blatter, 2009), providing the main components for the steady-state experiments presented in this study.

\subsection{Input data}

The observed ice-sheet geometry is derived from the BEDMAP2 dataset (Fretwell and others, 2013), including bedrock elevation, ice-surface topography, and ice sheet and shelf thickness. The original $1 \mathrm{~km}$-resolution data are regridded to a horizontal resolution of $10 \mathrm{~km}$, currently representing one of the highest resolutions computationally viable for long-term (hundreds of thousands of years), continental-scale forward ice-sheet modelling. BEDMAP2 is a compilation of 24.8 million ice thickness data points obtained from a variety of sources including airborne and over-snow radar surveys, satellite altimetry, seismic sounding data and satellite gravimetry (Fretwell and others, 2013). Complemented by surface elevation data from several DEMs to derive previously unknown bedrock features, this compilation allows for a detailed modelling of the Antarctic ice sheet-shelf system.

The geothermal heat flux map of Fox Maule and others (2005) is prescribed at the base of a modelled lithospheric layer, and the thermal effect at the base of the ice sheet is computed using a temperature equation that balances local temperature changes with advection and heat conduction (Greve and Blatter, 2009). Atmospheric conditions at the surface of the ice sheet and ice shelves, including nearsurface $(2 \mathrm{~m})$ air temperatures and precipitation rates, are obtained from the regional climate model RACMO2.3 (henceforth RACMO, van Wessem and others, 2014), averaged over the period 1979-2010. RACMO is forced at its boundaries by reanalysis data from ERA-Interim over the same period (Dee and others, 2011). In the interior of the domain the Antarctic climate conditions are modelled with a horizontal resolution of $27 \mathrm{~km}$ and 40 levels in the vertical direction. RACMO contains modules specifically implemented for glaciated regions, including a multilayer snow model, and compares well with in situ observations (van Wessem and others, 2014). 
The precipitation rates and near-surface air temperatures are used to compute the accumulation rates following the relation of Marsiat (1994). Temperatures are adjusted to changes in topography through a simple lapse-rate correction of $0.008^{\circ} \mathrm{C} \mathrm{m}^{-1}$. Surface melt is computed using a positive degree-day (PDD; Reeh, 1991; Calov and Greve, 2005) scheme with melt factors $\beta_{\text {snow }}=3$ and $\beta_{\text {ice }}=8 \mathrm{~mm}$ i.e. day ${ }^{-1}{ }^{\circ} \mathrm{C}^{-1}$ for snow and ice, respectively. All forcing datasets have been projected onto the same polar stereographic grid used for the BEDMAP2 data, with a horizontal resolution of $10 \mathrm{~km}$ for the main simulation, and 20 and $40 \mathrm{~km}$ resolutions for the sensitivity experiments presented in Section 3.2.

\subsection{Experimental set-up}

The initial bedrock-, sea floor- and basal and surface ice elevations relative to the present-day sea level are defined using the $10 \mathrm{~km}$-spaced topographic data from BEDMAP2 (see Section 2.2). The model domain embraces the entire Antarctic ice sheet-shelf system and the surrounding Southern Ocean, and contains $601 \times 601$ equidistant gridpoints in the horizontal direction, and 81 gridpoints in the vertical direction (densifying towards the base), used for the computation of the temperature and velocity fields. Below the ice sheet, additional 41 gridpoints form the modelled lithospheric thermal layer. The ice flow enhancement factors for the SIA and SSA are set to the values $E_{\mathrm{SIA}}=1$ and $E_{\mathrm{SSA}}=0.5$, respectively. The initial ice temperature for the entire model grid is set to a homogeneous value of $-10^{\circ} \mathrm{C}$ (results do not depend on this initial choice). Then, external forcing datasets are prescribed at the boundaries of the system (see Section 2.2): the time-invariant geothermal heat flux data are prescribed as the lower boundary of the thermal bedrock model used to compute the temperatures at the ice-sheet base, whereas the precipitation rates and near-surface temperature are used to compute the surface mass balance and ice-surface temperatures.

From this configuration, the model is run forward in time in four main stages designed to provide a model spin-up and the calibration of two key quantities: the spatial distribution of the basal drag coefficient for the grounded ice sheet, and the basal melting/freezing rates for the floating ice shelves. Initial values for both quantities are $1 \mathrm{~m} \mathrm{a}^{-1} \mathrm{~Pa}^{-1}$ and $0 \mathrm{~m} \mathrm{a}^{-1}$, respectively, corresponding to a rough bedrock that opposes basal sliding and no melt or accretion at the base of ice shelves. Throughout the simulations, the grounding line and ice-shelf fronts are kept at their modern positions in order to ensure a consistent model calibration (Bernales and others, 2017). In the first stage, the model solves the evolution equations for temperature, velocity and thickness every 5 model-years, during a simulation period of 50000 years. The distinct feature of this stage is that it scales the evolution of the ice thickness by a factor of $10^{-3}$, keeping the ice thickness close to its initial (i.e. observed) value (Bernales and others, 2017). This allows for an initialisation of the ice-sheet thermodynamics that is not contaminated by artificial changes in the ice geometry. In contrast to a fixed-topography approach (e.g. Pattyn, 2010; Sato and Greve, 2012), this procedure allows for an evolution of the ice thickness and thus for a continuous calibration of the basal sliding coefficients and basal melt rates during the entire simulation. In addition, it can be combined with a much larger time step (that would otherwise generate numerical instabilities) and ensures that the temperature within the ice can reach an equilibrium with time-invariant boundary conditions at a normal pace, considerably speeding up the simulations.

In the grounded ice sheet, changes in the ice thickness are tracked by a calibration algorithm that adjusts the basal drag coefficient at each grid-point every 50 model-years to locally minimise the difference between the modelled and observed (i.e. initial) ice thickness. This procedure is based on the idea of Pollard and DeConto (2012), which is explored and modified by Bernales and others (2017). In the floating ice shelves, a similar algorithm adjusts the magnitude of the basal melting or freezing rates every 20 years, keeping the ice shelves close to their observed thickness, following:

$$
\mathrm{BMR}^{*}=\mathrm{BMR}+F_{\mathrm{tan}} \cdot \tan \left(\frac{H-H_{0}}{H_{\mathrm{scl}}}\right),
$$

where $\mathrm{BMR}^{*}$ and $\mathrm{BMR}$ are the current and previous basal melting rates (representing freezing if negative), respectively, $H$ and $H_{0}$ are the current (modelled) and reference (from BEDMAP2) ice thicknesses, the parameter $F_{\text {tan }}=1.725$ scales the adjustment and $H_{\mathrm{scl}}=100 \mathrm{~m}$ is a scaling factor introduced to prevent overshoots. For the same reason, the argument of the trigonometric function is restricted to a range -1.5 to +1.5 (see Table 2 for experiments with different parameter choices).

The second and third stages use the same set-up (starting from the results of the previous stage), but instead scale the ice-thickness evolution by factors of $10^{-2}$ and $10^{-1}$, respectively. The final stage involves an unscaled evolution of the ice thickness, solving the thermodynamical model equations every 0.5 years until an equilibrium is reached. These four stages enable a fast, stable convergence towards an equilibrium ice-sheet state. The steady-state experiments presented in this study provide the spatial distribution of basal melting and freezing rates required to keep the Antarctic ice shelves in equilibrium for the simulated dynamical state with a fixed grounding line (see the Supplementary Materials for an analysis of the effects of this constraint). In order to allow for a direct comparison with the observation-based estimates of Rignot and others (2013) and Depoorter and others (2013), we add (during the post-processing) observation-based iceshelf thinning rates (Pritchard and others, 2012) to our steady-state estimates, as a proxy for the 'non-steady-state' melt rates. This procedure is qualitatively equivalent to that of Rignot and others (2013) and Depoorter and others (2013), since these studies use the mass conservation to determine the $\mathrm{BMB}$, while adding the ice-shelf thinning rates to account for a non-equilibrium behaviour. However, the cited studies use 2007/08 ice-surface velocities (Rignot and others, 2011), which are not necessarily in equilibrium. A comparison between our steady-state ice velocities and the velocities used in Rignot and others (2013) and Depoorter and others (2013) is presented as part of the results (Section 3.1).

\section{RESULTS AND DISCUSSION}

\subsection{Retrieved basal mass balance of ice shelves}

In this section we present the estimated ice-shelf $\mathrm{BMB}$ from our simulations of the present-day Antarctic ice sheet, which have been run to an equilibrium with the modern climate conditions. The retrieved distribution of basal 


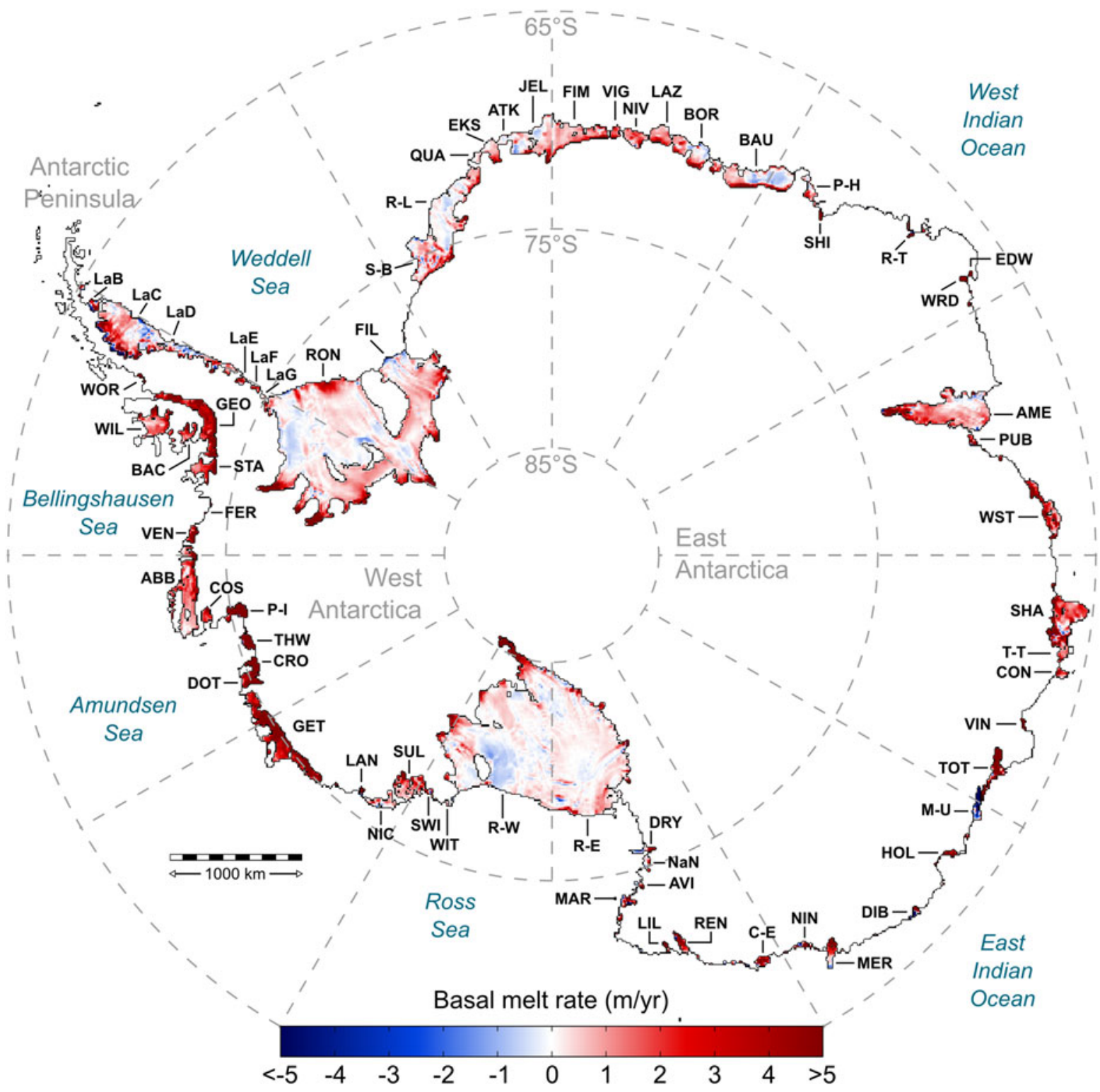

Fig. 1. Predicted basal melting (freezing if negative) rates of Antarctic ice shelves, in metres of ice per year. Modern ice-shelf thinning rates (Pritchard and others, 2012) are added to account for a non-steady-state behaviour. See Table 1 for details.

melting and freezing rates beneath the Antarctic ice shelves (Fig. 1) is far from being homogeneous, with alternating zones of melting and freezing. The presence of accretion zones is clearly visible under the largest ice shelves (Ronne, Filchner, Ross East and Ross West; see Figure 1 for a location map and Table 1 for abbreviations). Noticeable accretion zones are also present along the coast of East Antarctica, from the Stancomb-Brunt to Prince Harald ice shelves. Overall, the distribution of melting and freezing zones is similar to that of Rignot and others (2013), where melting is strongest near grounding lines and ice shelf fronts, while freezing mostly occurs under the central parts of ice shelves (see Supplementary Fig. S2). In addition, we retrieve a predominant melting under the smaller ice shelves whose grounding lines are close to the calving fronts, where the smooth basal topography and small iceshelf extents prohibit an accretion from ice-shelf-water plumes (Depoorter and others, 2013). Unexpectedly high rates of basal melting along the East Antarctic coast reported by Rignot and others (2013) and Depoorter and others (2013) are also reproduced by our model, particularly near grounding lines. In addition, we infer a predominant subshelf melting in the West and East Indian Oceans, between the Shirase and Totten ice shelves. As for individual ice shelves, our retrieved patterns closely resemble those from Rignot and others (2013) in most areas, with striking similarities in the sub-shelf melting/freezing patterns of the large ice shelves near the ice fronts (see Supplementary Fig. S2).

Our estimate of the total ice-shelf steady-state BMB is $-1648.7 \mathrm{Gt} \mathrm{a}^{-1}$, which increases to $-1917 \mathrm{Gt} \mathrm{a}^{-1}$ when the observational ice-shelf thinning rates of Pritchard and others (2012) are taken into account. The latter value is larger than the estimates of Rignot and others (2013) $\left(-1500 \pm 237 \mathrm{Gt} \mathrm{a}^{-1}\right)$ and Depoorter and others (2013) $\left(-1454 \pm 174 \mathrm{Gt} \mathrm{a}^{-1}\right)$. The degree of agreement, however, varies for different Antarctic sectors. Our estimates in both the Antarctic Peninsula and West Antarctica are relatively closer to the observation-based studies than in East Antarctica, where our values are considerably higher. This difference reflects generally higher rates of basal melting for many ice shelves, especially near grounding lines required by the model to replicate the observed ice-shelf thickness. 
Table 1. Description of individual characteristics of the Antarctic ice shelves, including modelled surface mass balance (SMB), groundingline flux (GL), ice-front flux (IF), basal mass balance (BMB) and basal melting rate (BMR, with positive values representing melting).

\begin{tabular}{|c|c|c|c|c|c|c|c|}
\hline Name & Code & $\begin{array}{l}\text { Area } \\
\mathrm{km}^{2}\end{array}$ & $\begin{array}{l}\mathrm{SMB} \\
\mathrm{Gt} \mathrm{a}^{-1}\end{array}$ & $\begin{array}{l}\mathrm{GL} \\
\mathrm{Gt} \mathrm{a}^{-1}\end{array}$ & $\begin{array}{l}\text { IF } \\
\mathrm{Gt} \mathrm{a}^{-1}\end{array}$ & $\begin{array}{l}\mathrm{BMB} \\
\mathrm{Gt} \mathrm{a}^{-1}\end{array}$ & $\begin{array}{l}\mathrm{BMR} \\
\mathrm{m} \mathrm{a}^{-1}\end{array}$ \\
\hline Larsen B & $\mathrm{LaB}$ & 3568 & -0.4 & 20.7 & -13.3 & $-7.1 /-8.3$ & $2.0 / 2.3$ \\
\hline Larsen C & $\mathrm{LaC}$ & 47903 & 19.1 & 49.1 & -29.6 & $-39.6 /-40.8$ & $0.8 / 0.9$ \\
\hline Larsen D & LaD & 23584 & 9.6 & 29.8 & -3.6 & $-36.5 /-20.0$ & $1.5 / 0.8$ \\
\hline Larsen E & $\mathrm{LaE}$ & 1520 & 0.7 & 3.6 & -0.9 & $-3.5 /-3.4$ & $2.3 / 2.2$ \\
\hline Larsen F & $\mathrm{LaF}$ & 712 & 0.3 & 1.0 & -0.4 & $-0.9 /-1.4$ & $1.2 / 2.0$ \\
\hline Larsen G & LaG & 510 & 0.2 & 0.5 & -0.3 & $-0.3 /-0.3$ & $0.5 / 0.5$ \\
\hline Wordie & WOR & 594 & 0.6 & 18.4 & -7.2 & $-11.9 /-11.2$ & $20.1 / 18.8$ \\
\hline George VI & GEO & 24276 & 11.7 & 70.6 & -6.7 & $-77.2 /-92.1$ & $3.2 / 3.8$ \\
\hline Wilkins & WIL & 14256 & 10.1 & 14.9 & -1.7 & $-23.8 /-27.4$ & $1.7 / 1.9$ \\
\hline Bach & $\mathrm{BAC}$ & 3924 & 1.3 & 7.7 & -1.1 & $-7.9 /-10.5$ & $2.0 / 2.7$ \\
\hline Stange & STA & 7794 & 6.2 & 15.4 & -2.7 & $-19.1 /-24.7$ & $2.5 / 3.1$ \\
\hline Antarctic Peninsula & & 128640 & 58.9 & 232.1 & -66.9 & $-228.8 /-241.0$ & 1.8/1.9 \\
\hline Ronne & RON & 336834 & 62.7 & 215.1 & -88.1 & $-184.4 /-229.0$ & $0.5 / 0.7$ \\
\hline Ferrigno & FER & 102 & 0.1 & 3.3 & -2.0 & $-1.2 /-4.7$ & $11.8 / 46.5$ \\
\hline Venable & VEN & 3136 & 3.6 & 12.7 & -8.4 & $-8.0 /-14.9$ & $2.6 / 4.8$ \\
\hline Abbot & $\mathrm{ABB}$ & 31808 & 28.0 & 33.6 & -7.6 & $-54.9 /-51.5$ & $1.7 / 1.6$ \\
\hline Cosgrove & COS & 2940 & 1.7 & 4.5 & -1.9 & $-4.4 /-7.0$ & $1.5 / 2.4$ \\
\hline Pine Island & P-I & 5920 & 5.0 & 77.1 & -27.8 & $-55.1 /-82.2$ & $9.3 / 13.9$ \\
\hline Thwaites & THW & 4494 & 4.0 & 71.9 & -34.9 & $-42.0 /-63.0$ & $9.3 / 14.0$ \\
\hline Crosson & $\mathrm{CRO}$ & 3165 & 3.3 & 18.3 & -4.5 & $-17.4 /-34.4$ & $5.5 / 10.9$ \\
\hline Dotson & DOT & 5402 & 5.5 & 19.7 & -2.7 & $-22.8 /-37.5$ & $4.2 / 6.9$ \\
\hline Getz & GET & 34211 & 33.4 & 76.0 & -27.2 & $-84.0 /-147.5$ & $2.5 / 4.3$ \\
\hline Land & LAN & 717 & 0.7 & 11.2 & -4.6 & $-7.0 /-6.6$ & $9.7 / 9.3$ \\
\hline Nickerson & NIC & 6455 & 4.4 & 6.1 & -3.8 & $-6.9 /-3.9$ & $1.1 / 0.6$ \\
\hline Sulzberger & SUL & 13392 & 7.9 & 21.5 & -1.7 & $-28.2 /-25.7$ & $2.1 / 1.9$ \\
\hline Swinburne & SWI & 928 & 0.8 & 3.1 & -1.5 & $-2.3 /-2.2$ & $2.5 / 2.4$ \\
\hline Withrow & WIT & 412 & 0.2 & 0.6 & -0.6 & $-0.2 /-0.2$ & $0.6 / 0.5$ \\
\hline Ross West & R-W & 303621 & 29.7 & 98.5 & -67.7 & $-57.8 /-51.9$ & $0.2 / 0.2$ \\
\hline Other & & 615 & 0.4 & 12.2 & -5.7 & $-7.0 /-$ & $11.3 /-$ \\
\hline West Antarctica & & 754152 & 192.2 & 690.4 & -288.1 & $-592.0 /-788.8$ & $0.8 / 1.0$ \\
\hline Filchner & FIL & 101237 & 12.3 & 92.8 & -29.9 & $-72.4 /-84.9$ & $0.7 / 0.8$ \\
\hline Stancomb-Brunt & S-B & 37666 & 13.8 & 22.4 & -8.4 & $-28.3 /-24.3$ & $0.8 / 0.6$ \\
\hline Riiser-Larsen & $\mathrm{R}-\mathrm{L}$ & 43199 & 14.8 & 21.0 & -9.8 & $-26.4 /-15.4$ & $0.6 / 0.4$ \\
\hline Quar & QUA & 2103 & 0.6 & 0.9 & -1.3 & $-0.2 /-0.6$ & $0.1 / 0.3$ \\
\hline Ekstroem & EKS & 6502 & 3.1 & 5.5 & -1.8 & $-6.9 /-7.0$ & $1.1 / 1.1$ \\
\hline Atka & ATK & 2195 & 1.1 & 0.6 & -0.7 & $-1.0 /-0.3$ & $0.5 / 0.1$ \\
\hline Jelbart & JEL & 35539 & 17.1 & 25.8 & -10.2 & $-33.0 /-27.8$ & $0.9 / 0.8$ \\
\hline Fimbul & FIM & 16346 & 6.2 & 20.4 & -6.5 & $-20.1 /-23.1$ & $1.2 / 1.4$ \\
\hline Vigrid & VIG & 2488 & 1.0 & 3.5 & -1.8 & $-2.8 /-4.7$ & $1.1 / 1.9$ \\
\hline Nivl & NIV & 7369 & 3.1 & 10.1 & -3.8 & $-9.5 /-8.9$ & $1.3 / 1.2$ \\
\hline Lazarev & LAZ & 8645 & 3.4 & 7.5 & -3.4 & $-7.6 /-10.9$ & $0.9 / 1.3$ \\
\hline Borchgrevnik & BOR & 20609 & 8.5 & 26.6 & -15.0 & $-20.3 /-20.0$ & $1.0 / 1.0$ \\
\hline Baudouin & BAU & 32912 & 10.6 & 34.9 & -14.8 & $-31.2 /-22.8$ & $0.9 / 0.7$ \\
\hline Prince Harald & $\mathrm{P}-\mathrm{H}$ & 5543 & 4.8 & 7.9 & -5.2 & $-7.9 /-5.0$ & $1.4 / 0.9$ \\
\hline Shirase & $\mathrm{SHI}$ & 696 & 0.2 & 24.0 & -5.2 & $-18.2 /-17.1$ & $26.2 / 24.7$ \\
\hline Rayner-Thyer & R-T & 881 & 0.4 & 11.0 & -1.4 & $-9.4 /-9.7$ & $10.7 / 11.0$ \\
\hline Edward VIII & EDW & 389 & 0.4 & 2.9 & -1.3 & $-2.1 /-2.6$ & $5.4 / 6.7$ \\
\hline Wilma-Robert-Downer & WRD & 780 & 0.5 & 13.0 & -0.6 & $-13.1 /-13.1$ & $16.8 / 16.8$ \\
\hline Amery & AME & 60970 & 11.9 & 87.8 & -17.5 & $-80.7 /-100.1$ & $1.3 / 1.6$ \\
\hline Publications & PUB & 1588 & 0.1 & 9.3 & -3.7 & $-5.6 /-5.5$ & $3.5 / 3.5$ \\
\hline West & WST & 15098 & 8.1 & 48.5 & -21.5 & $-35.5 /-47.1$ & $2.4 / 3.1$ \\
\hline Shackleton & SHA & 29307 & 20.1 & 60.4 & -24.0 & $-57.3 /-88.7$ & $2.0 / 3.0$ \\
\hline Tracy-Tremenchus & $\mathrm{T}-\mathrm{T}$ & 2319 & 1.1 & 1.6 & -0.3 & $-2.6 /-3.6$ & $1.1 / 1.5$ \\
\hline Conger & $\mathrm{CON}$ & 2510 & 1.6 & 1.9 & -1.1 & $-2.5 /-3.9$ & $1.0 / 1.6$ \\
\hline Vincennes & VIN & 875 & 0.5 & 23.3 & -10.8 & $-13.5 /-13.5$ & $15.5 / 15.5$ \\
\hline Totten & TOT & 8286 & 9.1 & 115.2 & -34.8 & $-92.1 /-103.3$ & $11.1 / 12.5$ \\
\hline Moscow University & $\mathrm{M}-\mathrm{U}$ & 4286 & 2.8 & 30.5 & -19.3 & 18.1/18.2 & $-4.2 /-4.2$ \\
\hline Holmes & $\mathrm{HOL}$ & 1654 & 2.7 & 22.3 & -16.8 & $-8.7 /-9.6$ & $5.3 / 5.8$ \\
\hline Dibble & DIB & 1551 & 1.7 & 15.8 & -13.2 & $-4.4 /-5.9$ & $2.8 / 3.8$ \\
\hline Mertz & MER & 5761 & 4.1 & 25.4 & -8.5 & $-21.1 /-18.2$ & $3.7 / 3.2$ \\
\hline Ninnis & NIN & 1868 & 1.2 & 29.6 & -18.6 & $-12.5 /-10.8$ & $6.7 / 5.8$ \\
\hline Cook East & C-E & 2954 & 1.6 & 21.8 & -11.9 & $-12.0 /-8.5$ & $4.1 / 2.9$ \\
\hline Rennick & REN & 3295 & 0.8 & 11.7 & -0.8 & $-11.7 /-13.7$ & $3.6 / 4.2$ \\
\hline Lillie & LIL & 799 & 0.3 & 10.8 & -1.0 & $-10.1 /-10.1$ & $12.6 / 12.6$ \\
\hline Mariner & MAR & 2836 & 1.4 & 6.6 & -4.4 & $-3.9 /-3.6$ & $1.4 / 1.3$ \\
\hline
\end{tabular}


Table 1. (Cont.)

\begin{tabular}{|c|c|c|c|c|c|c|c|}
\hline Name & Code & $\begin{array}{l}\text { Area } \\
\mathrm{km}^{2}\end{array}$ & $\begin{array}{l}\mathrm{SMB} \\
\mathrm{Gt} \mathrm{a}{ }^{-1}\end{array}$ & $\begin{array}{l}\mathrm{GL} \\
\mathrm{Gt} \mathrm{a}^{-1}\end{array}$ & $\begin{array}{l}\mathrm{IF} \\
\mathrm{Gt} \mathrm{a}\end{array}$ & $\begin{array}{l}\mathrm{BMB} \\
\mathrm{Gt} \mathrm{a}\end{array}$ & $\begin{array}{l}\text { BMR } \\
\mathrm{m} \mathrm{a}^{-1}\end{array}$ \\
\hline Aviator & AVI & 914 & 0.2 & 2.9 & -0.9 & $-2.3 /-2.5$ & $2.5 / 2.6$ \\
\hline Drygalsky & DRY & 2864 & 0.3 & 9.1 & -4.2 & $-5.5 /-5.9$ & $1.9 / 2.0$ \\
\hline Ross East & R-E & 193692 & 32.9 & 71.2 & -26.0 & $-78.2 /-88.7$ & $0.4 / 0.4$ \\
\hline Other & & 7208 & 3.1 & 73.9 & -44.8 & $-32.1 /-$ & $4.4 /-$ \\
\hline Total Antarctica & & 1560567 & 453.7 & 1986.5 & -760.4 & $-1648.7 /-1917.0$ & 1.1/1.2 \\
\hline
\end{tabular}

BMB and BMR values include equilibrium (left) and non-steady-state (right) values. BMR values are in w.e., computed using a reference ice density of $910 \mathrm{~kg} \mathrm{~m}^{-3}$. Text in bold indicates total values for the three major ice sheet sectors and the entire Antarctic ice sheet-shelf system. All values are corrected for area distortions caused by the polar stereographic projection following Snyder (1987).

These are the areas where the model calibration of the ice-shelf $\mathrm{BMB}$ compensates for any excess of influx - relative to an equilibrium - from the grounded ice sheet. We partly attribute our higher estimates to a combination of the following effects:

1. Compared with Rignot and others (2013) and Depoorter and others (2013), our numerical simulations of the Antarctic ice sheet-shelf system make use of the nearsurface temperature and precipitation rate model output from a more recent version of the regional atmospheric model RACMO (van Wessem and others, 2014). The two versions (RACMO2.3 here and RACMO2.1 in the cited studies) differ in their representation of the atmospheric conditions over East Antarctica, with RACMO2.3 generating considerably wetter conditions dominated by higher snowfall rates (van Wessem and others, 2014) and therefore a higher ice flux of 1061.7 $\mathrm{Gta}^{-1}$ into the ice shelves, compared with $782 \pm 80 \mathrm{Gt} \mathrm{a}^{-1}$ used by Rignot and others (2013).

2. Our calibration of basal melt rates requires a steady influx of ice mass from the grounded glaciers, which is achieved through the calibration of the ice-sheet model using an assumption of an equilibrium with the present-day climate conditions, as described in Section 2. An inclusion of the observed ice-sheet elevation changes during

Table 2. Summary of the sensitivity experiments performed in this study, including: experiment name-code adopted in text, short description of the difference with respect to the reference experiment REF, number of figure(s) in text, horizontal grid resolution $(\Delta x, y)$, mean absolute error in the ice thickness after equilibrium $(\bar{\Delta} H)$, total basal mass balance (BMB) and area-averaged basal melting rate (BMR). BMB and BMR values include equilibrium (left) and non-steady-state (right) values.

\begin{tabular}{|c|c|c|c|c|c|c|}
\hline Experiment & Short description & Figure & $\begin{array}{l}\Delta x, y \\
\mathrm{~km}\end{array}$ & $\begin{array}{l}\bar{\Delta} H \\
\mathrm{~m}\end{array}$ & 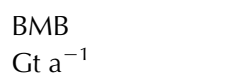 & $\begin{array}{l}\text { BMR } \\
\mathrm{m} \mathrm{a}^{-1}\end{array}$ \\
\hline REF & Reference simulation & 1,2 & 10 & 31.7 & $-1648.7 /-1917.0$ & $1.1 / 1.2$ \\
\hline GR20 & Horizontal grid resolution of $20 \mathrm{~km}$ & $3 d-f$ & 20 & 33.8 & $-1907.9 /-2180.8$ & $1.2 / 1.4$ \\
\hline GR40 & Horizontal grid resolution of $40 \mathrm{~km}$ & $3 g-i$ & 40 & 41.2 & $-2215.8 /-2470.4$ & $1.4 / 1.6$ \\
\hline BED & Perturbation of bed topography & $4 a-c$ & 20 & 29.2 & $-2282.6 /-2555.7$ & 1.5/1.7 \\
\hline GHF & Two-valued geothermal heat flux & $4 \mathrm{~d}-\mathrm{f}$ & 20 & 34.0 & $-1468.8 /-1742.0$ & $0.9 / 1.1$ \\
\hline ERA & ERA-Interim climate forcing & $4 g-i$ & 20 & 44.3 & $-1687.5 /-1960.7$ & $1.1 / 1.3$ \\
\hline HS-B & Hybrid scheme based on Bueler and Brown (2009) & - & 20 & 34.0 & $-2094.2 /-2367.4$ & 1.3/1.5 \\
\hline SoS & SIA-only scheme & - & 20 & 48.8 & $-2843.9 /-3117.0$ & $1.8 / 2.0$ \\
\hline SLD & Sliding law with $n=2$ & - & 20 & 32.8 & $-2074.9 /-2348.0$ & 1.3/1.5 \\
\hline ENHa & Ice-shelf enhancement factor set to $E_{\mathrm{SSA}}=1$ & - & 10 & 31.6 & $-1565.1 /-1833.4$ & 1.0/1.1 \\
\hline $\mathrm{ENHb}$ & Ice-shelf enhancement factor set to $E_{\mathrm{SSA}}=2$ & - & 10 & 31.6 & $-1465.1 /-1733.5$ & $0.9 / 1.0$ \\
\hline $\mathrm{ENHC}$ & Ice-shelf enhancement factor set to $E_{\mathrm{SSA}}=3$ & - & 10 & 31.7 & $-1391.3 /-1659.6$ & $0.9 / 1.0$ \\
\hline CAL1a & Calibration factor set to $F_{\mathrm{tan}}=1 \mathrm{~m}$ & _- & 10 & 31.7 & $-1631.7 /-1900.0$ & $1.1 / 1.2$ \\
\hline CAL1b & Calibration factor set to $F_{\tan }=2 \mathrm{~m}$ & - & 10 & 31.7 & $-1631.9 /-1900.3$ & $1.1 / 1.2$ \\
\hline CAL2a & Calibration time step set to 5 years & - & 10 & 31.7 & $-1630.8 /-1899.1$ & $1.0 / 1.2$ \\
\hline CAL2b & Calibration time step set to 10 years & - & 10 & 31.7 & $-1631.0 /-1899.3$ & $1.1 / 1.2$ \\
\hline CAL2C & Calibration time step set to 50 years & - & 10 & 31.7 & $-1631.5 /-1899.8$ & $1.1 / 1.2$ \\
\hline CAL3a & Calibration scaling factor set to $H_{\mathrm{scl}}=50 \mathrm{~m}$ & - & 10 & 31.7 & $-1632.3 /-1900.6$ & $1.1 / 1.2$ \\
\hline CAL3b & Calibration scaling factor set to $H_{\mathrm{scl}}=200 \mathrm{~m}$ & - & 10 & 31.7 & $-1631.8 /-1900.1$ & $1.1 / 1.2$ \\
\hline CAL3C & Calibration scaling factor set to $H_{\mathrm{scl}}=500 \mathrm{~m}$ & _- & 10 & 31.7 & $-1630.9 /-1899.2$ & $1.0 / 1.2$ \\
\hline PDDa & PDD factors set to $\beta_{\text {snow,ice }}=3 \mathrm{~mm}_{\text {day }}{ }^{-1}{ }^{\circ} \mathrm{C}^{-1}$ & - & 20 & 33.8 & $-1904.4 /-2177.6$ & $1.2 / 1.4$ \\
\hline PDDb & PDD factors set to $\beta_{\text {snow, ice }}=5 \mathrm{~mm}_{\text {day }}{ }^{-1}{ }^{\circ} \mathrm{C}^{-1}$ & - & 20 & 33.8 & $-1911.3 /-2184.5$ & $1.2 / 1.4$ \\
\hline PDDc & PDD factors set to $\beta_{\text {snow, ice }}=11 \mathrm{~mm}$ day ${ }^{-1}{ }^{\circ} \mathrm{C}^{-1}$ & - & 20 & 33.8 & $-1892.7 /-2165.8$ & $1.2 / 1.4$ \\
\hline PDDd & PDD factors set to $\beta_{\text {snow, ice }}=15 \mathrm{~mm}$ day ${ }^{-1}{ }^{\circ} \mathrm{C}^{-1}$ & - & 20 & 33.7 & $-1901.4 /-2174.5$ & $1.2 / 1.4$ \\
\hline LRCa & Lapse-rate correction set to $6^{\circ} \mathrm{C} \mathrm{km}^{-1}$ & - & 20 & 33.7 & $-1895.9 /-2169.0$ & $1.2 / 1.4$ \\
\hline $\mathrm{LRCb}$ & Lapse-rate correction set to $7^{\circ} \mathrm{C} \mathrm{km}^{-1}$ & _- & 20 & 33.8 & $-1906.0 /-2179.1$ & $1.2 / 1.4$ \\
\hline LRCC & Lapse-rate correction set to $9^{\circ} \mathrm{C} \mathrm{km}^{-1}$ & _- & 20 & 33.9 & $-1908.4 /-2181.6$ & $1.2 / 1.4$ \\
\hline LRCd & Lapse-rate correction set to $10^{\circ} \mathrm{C} \mathrm{km}^{-1}$ & _- & 20 & 33.9 & $-1891.1 /-2164.2$ & $1.2 / 1.4$ \\
\hline
\end{tabular}

BMR values are in w.e., computed using a reference ice density of $910 \mathrm{~kg} \mathrm{~m}^{-3}$. All values are corrected for area distortions caused by the polar stereographic projection, following Snyder (1987). 
the calibration of continental-scale forward models is, at present, a very challenging task, due to orders-of-magnitude differences between the length of the observational record and the timescales over which these models operate. Thus, recent observations of the ice sheet thickening in East Antarctica (e.g. Davis and others, 2005; Pritchard and others, 2012; Shepherd and others, 2012) are not included; instead, the observation-inferred positive change in the ice mass is driven towards the ice shelves, where our calibration of basal melting rates accounts for it, thus producing higher estimates. The opposite can be observed in our results for the West Antarctic ice shelves, where the BMB estimates in areas where the ice sheet is thinning (e.g. the Amundsen Sea sector) are lower than those of Rignot and others (2013).

3 . In contrast to the observation-based studies, our method does not employ an external dataset of the observed ice-surface velocities, but instead uses the ice velocity computed by the ice model. We compare the resulting ice-surface velocities to the observational dataset of Rignot and others (2011) (Fig. 2). General characteristics of the observed Antarctic ice flow are well reproduced by the model, particularly in areas of rapid ice flow and across the transition zones between slow- and fastflowing ice sectors. The mean absolute difference between the observed and modelled surface ice velocities is $40.1 \mathrm{~m} \mathrm{a}^{-1}$. The largest error occurs at the location of the former Ice Stream C (Fig. 2f), the existence of which is predicted by the model regardless of its stagnant behaviour over the last 150 years (Hulbe and Fahnestock, 2007). Furthermore, ice velocities in some ice shelves (e.g. Ronne/Filchner, Amery and Stancomb-Brunt) are somewhat underestimated by the model, which we partly attribute to our choice of the ice flow enhancement factor in the computation of the SSA velocities (see Section 3.2). The computed ice velocities can also be affected by the assumption of an ice-sheet equilibrium with the present-day climate conditions, among other potential sources of uncertainty as discussed below. This may result in too-fast flow at the ice-sheet margins, especially near the observed ice stream locations (Bernales and others, 2017), requiring higher melting rates to account for the increased ice influx relative to observations. Figure 2 also shows the misfit between the modelled and observed ice thickness (Fretwell and others, 2013), with a mean absolute ice thickness error being equal to $31.7 \mathrm{~m}$. This misfit is significantly below the values that are usually found in modelling studies of the Antarctic ice sheet (Pollard and DeConto, 2012), mainly due to the calibration of the basal sliding coefficients in the grounded ice sheet and of basal melting and freezing rates under the floating ice sectors. The largest ice thickness errors occur in mountainous regions, where basal thermal conditions do not favour ice sliding and the calibration is not performed (Bernales and others, 2017).

In addition to the effects of the neglected non-steady-state behavior mentioned above, deviations from the observationbased estimates may be partly explained by other limitations of our method. These include a relatively coarse resolution of the model $(10 \mathrm{~km})$ when compared with that of Rignot and others (2013) and Depoorter and others (2013) (1 km for ice thickness and $450 \mathrm{~m}$ for ice velocities) that also influences the location of the grounding line and ice-front flux gates. As described in Section 2, our model employs a hybrid combination of the SIA and SStA to compute the ice-sheet velocities, which could be affected by the lack of the higher-order dynamics (e.g. Gagliardini and others, 2013), especially across the transition zones near grounding lines. The magnitude of such influences will be hopefully assessed, as soon as similar experiments become feasible using higher-order models. Additional limitations arise from the uncertainties in the input datasets required by our model (e.g. the geothermal heat flux, climate forcing and bedrock topography) that influence the modelled ice-sheet dynamics and thus the estimates of the ice-shelf $B M B$, although the observational methods are also affected by the uncertainties in the topographic and climate data. Another limitation of both our model-based and observational methods is that they only provide estimates of basal melting and freezing rates for the present-day ice-shelf configuration, and the direct applicability of the retrieved values for scenarios with grounding-line migration driven by, for example, climate variations is not ensured (see Supplementary Materials). In the following sections, we present additional experiments that explore the influence of some of these limitations and uncertainties on the estimated ice-shelf BMB.

The large accretion zones retrieved along the Antarctic Peninsula, under big ice shelves (Ronne, Filchner, Ross East and Ross West), and at the East Antarctic coasts (mainly between the Stancomb-Brunt and Prince Harald ice shelves) are found to contribute $+214 \mathrm{Gt} \mathrm{a}^{-1}$ to our total $\mathrm{BMB}$ estimate, covering more than a quarter of the total ice-shelf area. This significant contribution to the total BMB is commonly disregarded by existing parameterisations of ice/ocean interactions (e.g. Beckmann and Goosse, 2003; Holland and others, 2008). A potential workaround to compensate for the disregarded freezing would be to reduce the basal melt rates elsewhere to obtain an area-average value in agreement with observations. However, such option must ensure that the melt rates in key areas, such as grounding zones, are not significantly affected, to prevent artificial changes in the ice-shelf geometry.

Table 1 summarises our estimates of the ice-shelf $B M B$ and the corresponding area-averaged melting rates. Major characteristics of the retrieved $\mathrm{BMB}$ are presented in the form of sector- and ice-shelf-averaged estimates, which allow for a direct comparison with previous estimates from other methods. Although the horizontal grid resolution used in this study is at the limit of what is currently feasible for whole-Antarctica forward modelling experiments, deviations from the ice-shelf areal extents presented in previous studies are inevitable, due to their higher resolution $(\sim 100$ times). For many applications of ice-sheet models the grid resolution is very important, and we discuss it in a greater detail in the following section, where we present an analysis of potential sources of uncertainty on the reconstructed BMB of ice shelves.

Table 1 also presents the retrieved BMB for individual ice shelves, including the corresponding area-averaged basal melting rates. Average melt rates range from -4.2 (indicating freezing conditions under the Moscow University ice shelf, East Antarctica) to $46.5 \mathrm{~m} \mathrm{a}^{-1}$ (indicating melting conditions under the Ferrigno ice shelf, West Antarctica), showing a similar variability to that found by Rignot and others (2013). Our model predicts local ice-shelf basal melting 


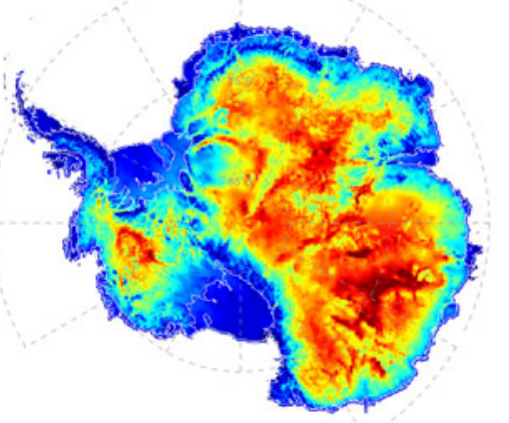

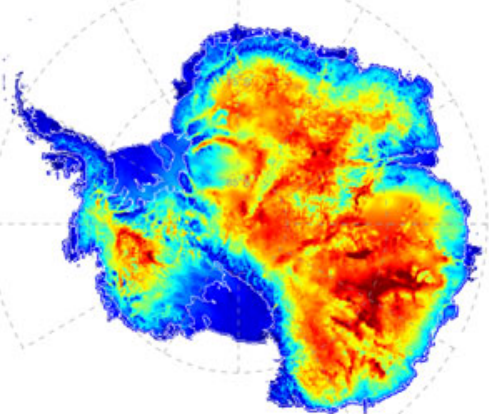

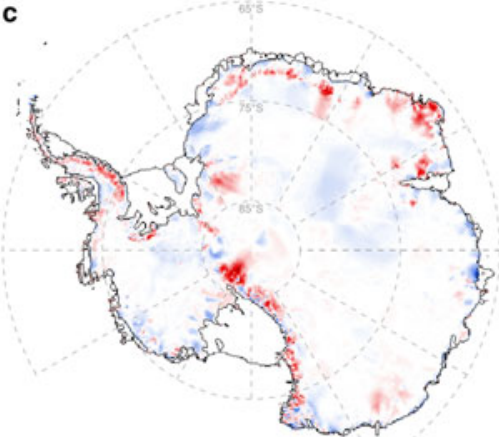

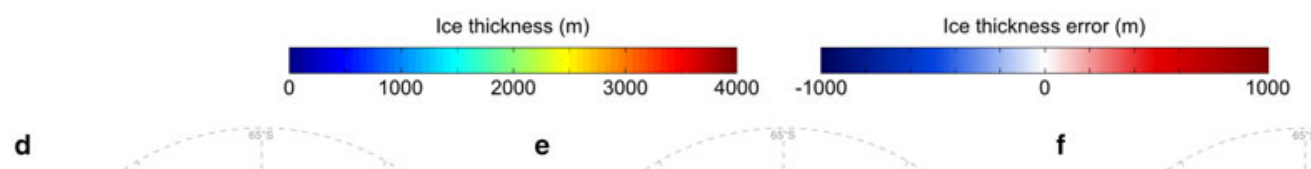

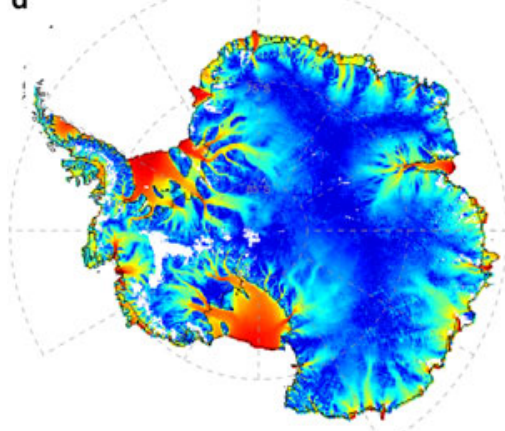

e

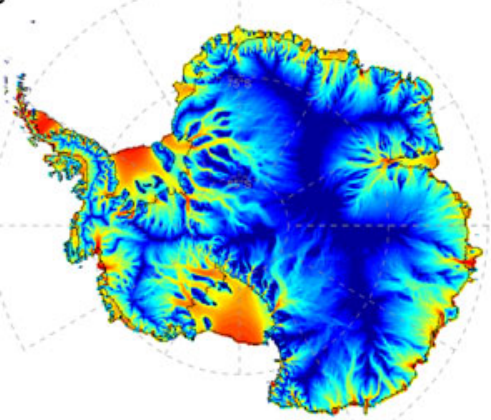

f

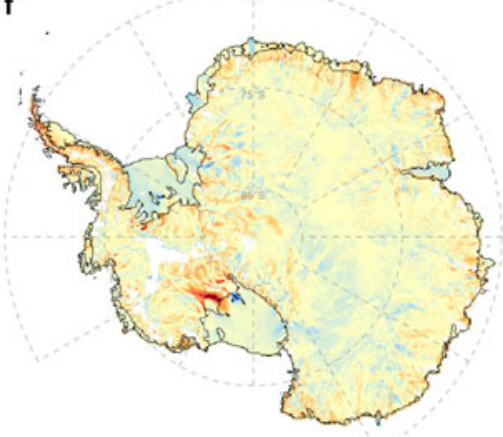

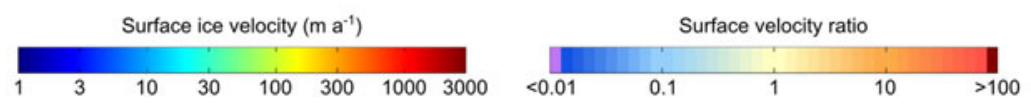

Fig. 2. Top row: Comparison between the observed (a) and the modelled (b) Antarctic ice thickness distribution, in metres, together with the corresponding ice-thickness error (c), in metres. Observational ice-thickness data are taken from Fretwell and others (2013). Bottom row: Comparison between the observed (d) and the modelled (e) Antarctic ice-surface velocities, in $\mathrm{m} \mathrm{a}^{-1}$, together with the ratio between the two $(\mathrm{f})$, excluding very low velocities $\left(<1 \mathrm{~m} \mathrm{a}^{-1}\right)$. Observational ice-velocity data are taken from Rignot and others $(2011)$.

rates ranging from $\sim-28$ to $\sim 103 \mathrm{~m} \mathrm{a}^{-1}$. The minimum value marks the accretion under the Moscow University ice shelf, whereas the maximum value is detected at the grounding line of the Pine Island ice shelf. Freezing rates similar to those predicted at the base of the Moscow University ice shelf can be found elsewhere but only in isolated points, which most likely originate from an insufficient ice influx from the grounded ice sheet caused by the low model grid resolution (relative to the observation-based studies). To keep the ice-shelf thickness close to observed, the calibration scheme compensates for the lack of resolution through unrealistic basal freezing rates near the grounding line. Other potential model deficiencies arising from its limited resolution are discussed in a greater detail in Section 3.2. Numerous areas with very high melting rates $\left(>25 \mathrm{~m} \mathrm{a}^{-1}\right)$ are found along the grounding lines of the Wordie, Ferrigno, Thwaites, Totten, Shackleton, Amery and Shirase ice shelves.

Grounding lines are known to exhibit melting rates that for many ice shelves are one-to-two orders of magnitude higher than area-average values (Rignot and others, 2002). Although some modelling studies have suggested sub-shelf melting rates with similar magnitudes (e.g. Payne and others, 2007), the implementation of such high rates is not commonplace in large-scale, long-term ice-sheet modelling experiments. Our model-based results support the idea that ice flow models developed to study the dynamics of ice sheet-shelf systems may over-simplify and underestimate the influence of the ocean thermal forcing when parameterisations (e.g. Beckmann and Goosse, 2003; Holland and others, 2008) are used. Although neither present-day observational data nor our estimates of melting and freezing rates can provide the necessary transient ice-shelf BMB for long-term simulations, our methodology and results can be used to aid the development of new parameterisations, which will be designed to fit the magnitudes and spatial patterns necessary to simulate the observed or hypothetical ice-sheet dynamical states under a variety of climate conditions.

\subsection{Exploration of uncertainties}

In this section, we present the results of modelling experiments that explore the influence of potential uncertainties in the input datasets and model formulation. We first analyse the sensitivity of the model results to a reduction of the model resolution in order to justify the use of a twofold lower resolution in our sensitivity tests relative to REF. Other than that, all presented experiments share identical model set-ups with the REF experiment (Section 2) presented in Figures 1 and 2, except for a change in the bedrock elevation boundary condition (BED simulation), geothermal forcing (GHF simulation) and climate forcing (ERA simulation). Furthermore, another set of simulations is carried out to assess the influence of a different basal sliding model, the use of a different hybrid scheme and a SIA-only model, and uncertainties in other model parameters on the modelled 
a

$20 \mathrm{~km}$

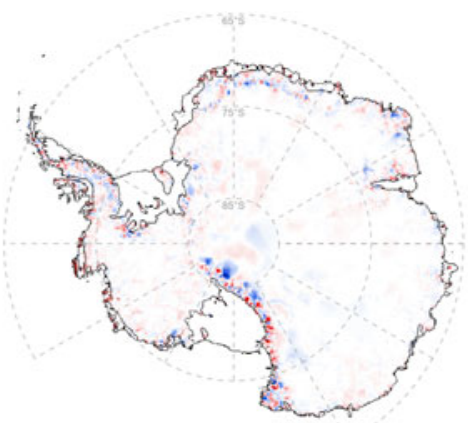

d

$40 \mathrm{~km}$
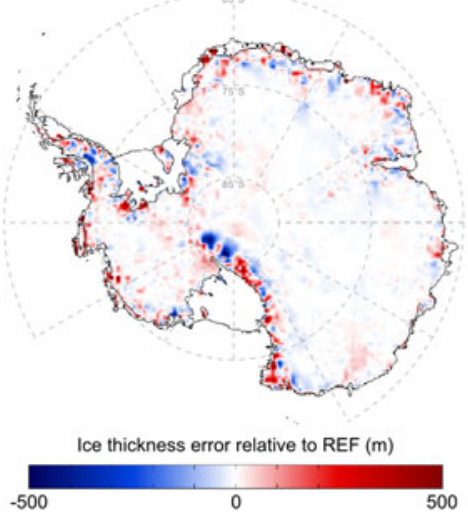

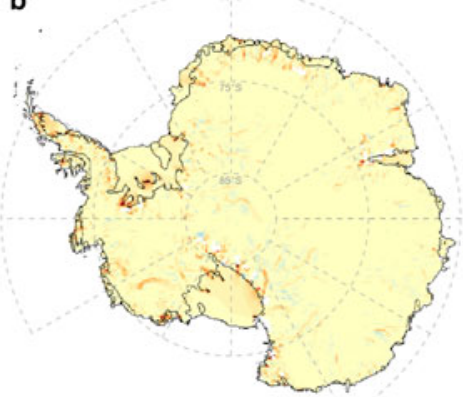

e

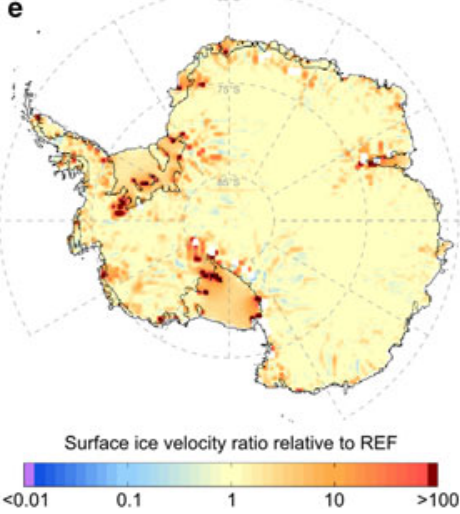

c

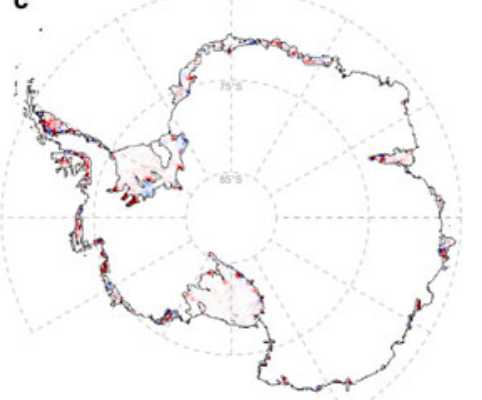

f

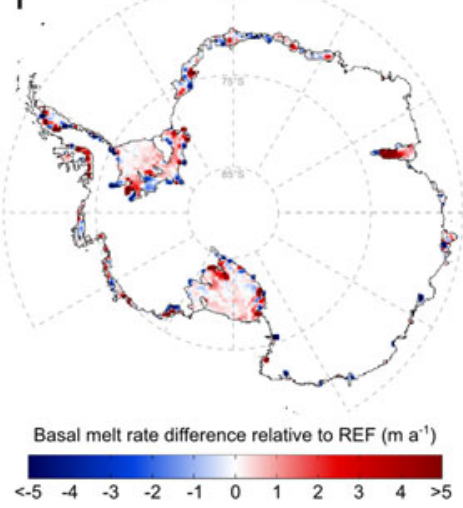

Fig. 3. Results of experiments that employ different horizontal grid resolutions, including $10 \mathrm{~km}$ (top row), $20 \mathrm{~km}$ (mid row) and $40 \mathrm{~km}$ (bottom row). Ice thickness errors (left column) and surface ice-velocity ratios (mid column) as in Figure 2, although relative to REF. Estimated basal melting and freezing rates (right column) computed as the difference relative to REF (see Fig. 1).

ice-shelf BMB and ice-sheet geometry. A summary of these sensitivity experiments is provided in Table 2.

\subsubsection{Influence of horizontal grid resolution}

The computational expenses of the long-term, continentalscale simulation presented in Section 3.1 remain very high due to its relatively high horizontal resolution, and thus it is of interest to assess the influence of using a coarser, more viable model grid on the BMB estimates.

Figure 3 shows a comparison of the retrieved basal melting and freezing rates at grid resolutions of 20 and $40 \mathrm{~km}$ (henceforth GR20 and GR40, respectively). On the one hand, GR20 shows a strong similarity to REF, displaying only minor discrepancies mostly occurring in the proximity of grounding lines due to the smoothing effects of a coarser grid, which locally amplify melting and freezing beneath ice shelves (e. g. in the Larsen D and Amery ice shelves). On the other hand, GR40 exhibits the pronounced effects of a much coarser grid resolution in the form of considerably larger zones of melting and freezing. Although in some areas the retrieved $\mathrm{BMB}$ of ice shelves seems to be nearly insensitive to a fourfold decrease in resolution to each horizontal direction (e.g. the Bellingshausen and Amundsen Sea sectors), there are areas where melting predicted by the reference run REF is alternated by freezing in GR40 and vice versa. An example of such resolution-induced artefacts is the Amery ice shelf, where the area of high basal melting predicted near the grounding line by REF and GR20 has extended towards the ice-shelf front in GR40, overtaking the freezing zone detected at higher resolutions. In addition, new spots of strong accretion are retrieved, especially under big ice shelves and to the north of the Antarctic Peninsula. Interestingly, a few ice-sheet sectors in GR40 display inverted patterns relative to those predicted by higher-resolution simulations. For example, the Moscow University ice shelf shows a predominant melting, whereas an accretion prevails beneath the Cook East ice shelf, showcasing the strong effects of a very coarse grid resolution.

The use of a finer model grid improves the agreement between our BMB estimates and those of Rignot and others (2013) and Depoorter and others (2013) (Table 2 and Supplementary Materials), which we attribute to a more localised (i.e. smaller area per grid cell) adjustment of basal melt rates and thus a reduced amplification of their estimated values near grounding lines, together with a more accurate representation of small-scale features in the modelled ice influx from the grounded ice sheet. Consequently, we expect that the use of grid resolutions higher than our reference resolution $(10 \mathrm{~km})$ will further reduce these discrepancies. Our analysis suggests that the use of grid resolutions coarser than $20 \mathrm{~km}$ produces melting/freezing patterns and magnitudes that disagree with the results of higher resolution experiments and observation-based estimates, potentially leading to strong biases in ice-sheet simulations. Based on the good agreement between GR20 and REF, a resolution of $20 \mathrm{~km}$ is used in some of the numerous sensitivity tests presented in the next sections to reduce the computation time (see Table 2).

\subsubsection{Influence of the input datasets}

As described in Section 2, the experiments presented in this paper use the BEDMAP2 dataset as a reference topography against which the basal ice-shelf melting and freezing rates are calibrated. Here, we run a $20 \mathrm{~km}$ resolution experiment (henceforth BED) where the bed topography is perturbed within the estimated uncertainty bounds (Fretwell and others, 2013) to assess potential impacts of such uncertainties on the retrieved BMB estimates. The perturbed bedrock is 


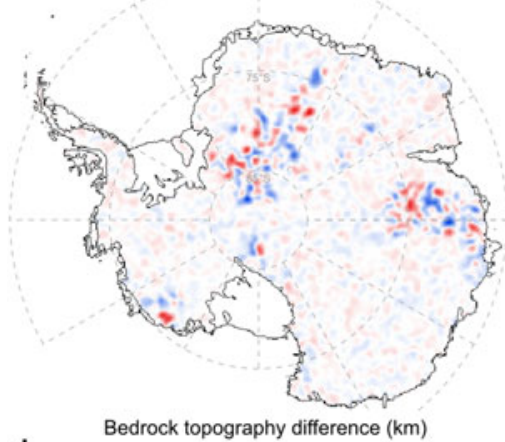

d

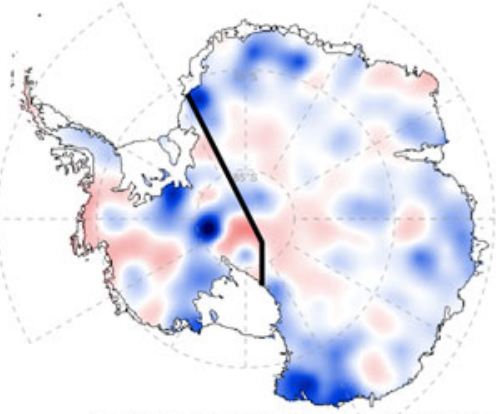

Geothermal heat flux difference $\left(x 10^{2} \mathrm{~mW} \mathrm{~m}^{-2}\right)$

g

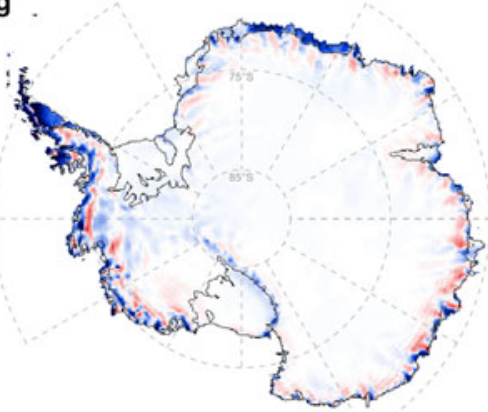

Surface mass balance difference $\left(\mathrm{m} \mathrm{yr}^{-1}\right)$ b

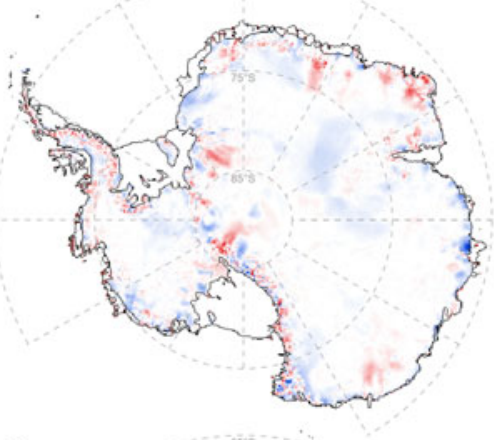

e

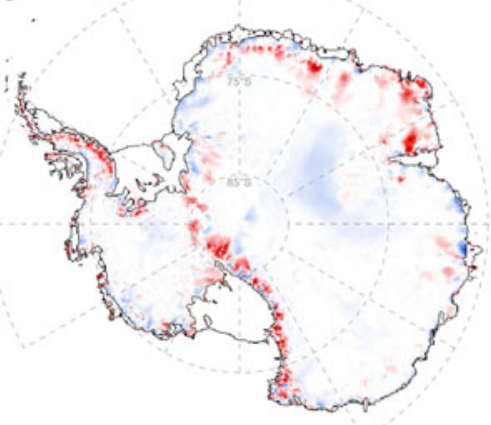

h

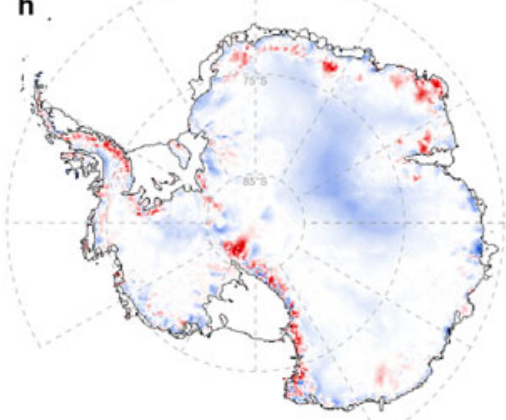

Ice thickness error relative to BEDMAP2 $(\mathrm{m})$

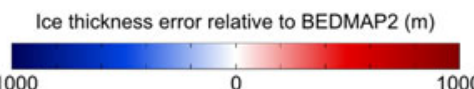

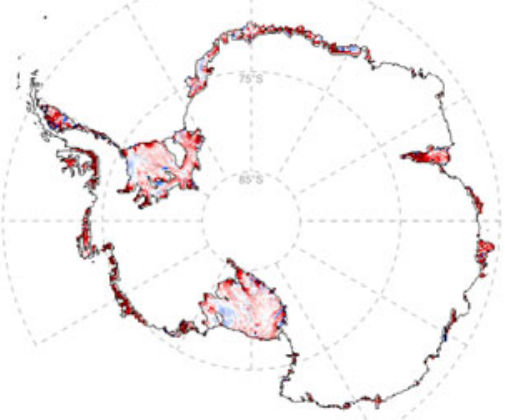

f

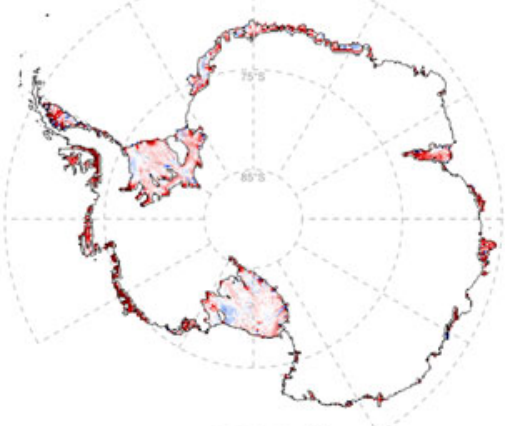

i

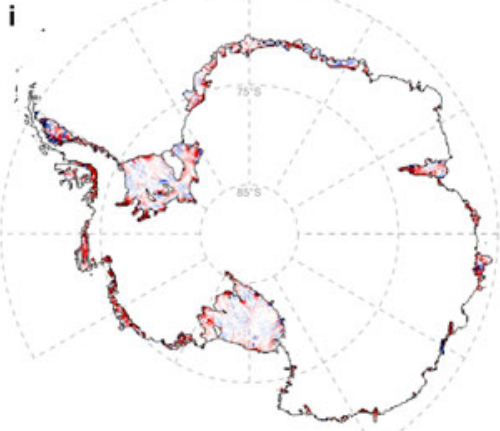

Basal melt rate $\left(\mathrm{m} \mathrm{a}^{-1}\right)$
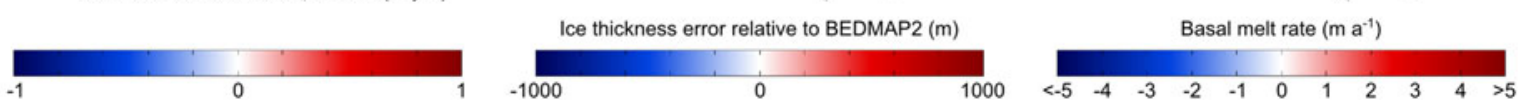

Fig. 4. Results of experiments utilising a perturbed BEDMAP2 bedrock topography based on the uncertainty estimates of Fretwell and others (2013) (top row), a two-valued geothermal heat flow distribution of Pollard and DeConto (2012) (mid row), and the climate forcing from the ERA-Interim reanalysis (bottom row; Dee and others, 2011). Thick black line in (d) represents the assumed division between East and West Antarctica. Left column shows the differences between the fields implemented in the above sensitivity tests and the REF experiment. Icethickness errors relative to BEDMAP2 (mid column) and estimated basal melting and freezing rates (right column) as in Figures 1, 2, respectively.

obtained by adding a randomly computed fraction of the uncertainty in the BEDMAP2 dataset to the reference topography (independently for each data gridpoint). The perturbation map has been smoothed in order to eliminate small-scale perturbations (below $100 \mathrm{~km}$ ) that tend to introduce numerical instabilities due to artificially strong horizontal gradients. Differences between the reference and the resulting perturbed bedrock topography (Fig. 4a) reach up to $\sim 500 \mathrm{~m}$, with the largest discrepancies occurring mostly in the areas of East Antarctica where the BEDMAP2 dataset is based on gravimetric data only (Fretwell and others, 2013). Compared with the experiment GR20, which is used here as a reference, the resulting ice-sheet equilibrium state has a smaller average absolute ice thickness error of $29.2 \mathrm{~m}$ (Table 2). This is due to a reduced overestimation of the modelled ice thickness over mountain ranges that we attribute to an enhanced ice drainage by new ice streams forming in areas where the bedrock topography has been lowered. This increment in the ice flow near the ice-sheet margins is also reflected in the new areas of icethickness underestimation (relative to GR20) surrounding the mountain ranges. An additional ice transport towards ice shelves increases the total ice-shelf $\mathrm{BMB}$ to a steadystate value of $-2282 \mathrm{Gt} \mathrm{a}^{-1}$, comparable with that of the GR40 simulation (Table 2), further demonstrating the strong impacts of the uncertainties in the topographic data on the estimated ice-shelf basal melting and freezing rates.

To test the influence of the uncertainties in the geothermal heat flux forcing, we perform a $20 \mathrm{~km}$ resolution experiment (henceforth GHF) featuring one of the simplest distributions commonly used in Antarctic ice-sheet simulations (e.g. Pollard and DeConto, 2012). In this simulation we adopt two different values for West and East Antarctica, a lower value of $54.6 \mathrm{~mW} \mathrm{~m}^{-2}$ under the East Antarctic ice sheet, and a higher value of $70.0 \mathrm{~mW} \mathrm{~m}^{-2}$ across West Antarctica. In contrast to the BED simulation, the GHF 
experiment produces an average absolute ice thickness error of $34 \mathrm{~m}$, which is close to that of GR20. Interestingly, the predicted total ice-shelf equilibrium BMB amounts to $-1468 \mathrm{Gt}$ $\mathrm{a}^{-1}$ and increases to $-1742 \mathrm{Gt}^{-1}$ when the observed icethinning rates are considered, which falls within the error bounds estimated by Rignot and others (2013). Such decrease in the total $\mathrm{BMB}$ is explained by a comparatively lower geothermal heat flux (relative to Fox Maule and others (2005) in REF) in such areas as those located upstream of the Ross West and Ronne ice shelves in West Antarctica, and most of the ice-stream locations along the East Antarctic coast (Fig. 4d). In these areas, the use of lower values of geothermal heat flux decreases the sliding potential of ice streams feeding the ice shelves, thereby reducing ice velocities and generating lower ice-shelf basal melting rates near the grounding lines. Similar to the bedrock topography, uncertainties in the geothermal heat flux forcing strongly impact the retrieved basal melting and freezing rates under ice shelves, which compensate for the differences in the predicted mass flux across the grounding line.

Finally, the climate forcing from the ERA-Interim reanalysis (Dee and others, 2011) is used in a $20 \mathrm{~km}$ resolution experiment (henceforth ERA) to test the influence of the uncertainties in the surface mass balance on the retrieved sub-shelf melting and freezing rates. The averaged precipitation rates and near-surface air temperatures are computed over the same period as the RACMO data (1979-2010) used in the REF experiment. A generally lower ice-sheet surface mass balance in the ERA-Interim dataset relative to RACMO (Fig. 4g) generates vast areas of an ice thickness underestimation, particularly in East Antarctica (Fig. 4h), producing a mean absolute ice thickness error of $44.3 \mathrm{~m}$. In addition, the reduced ice accumulation generates lower ice-shelf basal melting rates, which are similar to the estimates from the higher-resolution REF experiment. Thus, in ERA more wide-spread accretion zones decrease the total ice-shelf steady-state $\mathrm{BMB}$ to a value of $-1687.5 \mathrm{Gt} \mathrm{a}^{-1}$. As described in Section 2.2, the RACMO model is forced at its boundaries by the ERA-Interim reanalysis, and therefore the discrepancies between the ERA and GR20 experiments can be largely attributed to the regional, polar-oriented features implemented in RACMO. The higher resolution of RACMO allows for better resolved topographic gradients and circulation patterns, which may be critical for the simulation of such processes as, for example, the drifting snow transport (Lenaerts and others, 2012). Despite these discrepancies, the differences between the ERA-Interim and RACMO datasets are small compared with the outputs of general circulation models (e.g. Agosta and others, 2015). Based on our results, we expect that model initialisation procedures driven by climate forcing from a variety of general circulation models would produce essentially different results in order to compensate for the discrepancies between the model-based climate datasets. An analysis of the differences between the resulting ice-sheet model initialisations may provide insights into potential internal biases of these climate forcing datasets. However, such analysis is beyond the scope of this study and is therefore deferred to future work.

\subsubsection{Influence of the model formulation and parameters}

As a complement to the simulations exploring the uncertainties in the input datasets, we present the results of experiments that aim to assess the influence of model complexity and model parameter choices on the inferred iceshelf BMB. The hybrid combination of the SIA and SStA velocities presented in Section 2 (Eqn (1)) is a result of an original scheme formulation guided by our previous study (Bernales and others, 2017), where we compared the performance of different hybrid schemes during the calibration of an Antarctic ice sheet model. Among the tested hybrid combinations, the scheme based on the idea of Bueler and Brown (2009) (henceforth HS-B) performed well in terms of the model fit to the observed ice-sheet thickness and ice velocities. However, HS-B showed a somewhat reduced ability to minimise the ice thickness errors in the continental interior of East Antarctica, because in this scheme the computation of the SStA velocities is mainly limited to the fast-flowing ice-sheet margins. We test the influence of the differences between our original scheme used in GR20 and HS-B by running a $20 \mathrm{~km}$ simulation using the latter. Our results show that these different hybrid schemes exhibit a similar performance in terms of ice thickness and ice velocities. The estimated ice-shelf basal melting and freezing rates from GR20 and HS-B are also in a good agreement, with some minor differences due to small discrepancies induced by the formation of isolated ice streams that produce a higher ice-shelf $\mathrm{BMB}$ of $-2094.2 \mathrm{Gt} \mathrm{a}^{-1}$ for HS-B. As shown by Bernales and others (2017), the differences between hybrid schemes are masked by the calibration of the basal sliding coefficients. Since our computation of the ice-shelf $B M B$ depends on the ice flux from the grounded ice-sheet sectors (and not on specific values of basal sliding coefficients), the results are only affected by the discrepancies between the modelled ice thickness and velocity fields from both schemes.

In Bernales and others (2017) we also compared the performance of different hybrid schemes versus a scheme that uses only the SIA to model the grounded ice sectors (i.e. the SSA is used exclusively for the ice shelves) during the calibration of an Antarctic ice sheet model, showing that the latter approach produces larger misfits between the observed and modelled ice-sheet thickness and ice-surface velocities, especially near ice-sheet margins. Here we complement our sensitivity analysis by a comparison with this simpler approximation of the force balance equations, by performing an additional $20 \mathrm{~km}$ resolution experiment (henceforth SoS) using the above-mentioned SIA-only scheme. The increased mean absolute ice-thickness error of $48.8 \mathrm{~m}$ (Table 2) obtained from this experiment is accompanied by an even larger degradation of the estimated melting and freezing rates beneath ice shelves, producing a total steady-state BMB of $-2843.9 \mathrm{Gt} \mathrm{a}^{-1}$. Among all the experiments carried out in this study, the use of a SIA-only scheme for the grounded ice sectors has the largest impact on the retrieved ice-shelf $\mathrm{BMB}$, stressing the need for a realistic treatment of the rapidly flowing ice-sheet sectors, where the SIA is no longer valid.

In this study, we ensure a good agreement between the modelled and observed ice-sheet thickness through the calibration of basal sliding coefficients that enter our reference sliding law. In this sliding model (see Bernales and others, 2017, Eqns (2)-(6)) basal velocities are assumed to be proportional to the third power of the basal shear stress $(n=3)$, but in principle other choices are possible. For example, the sliding model of Pollard and DeConto (2012) uses a weaker non-linear relation $(n=2)$ during the calibration of 
the basal sliding coefficients. Here we test the influence of such change in the sliding law on our results by performing a $20 \mathrm{~km}$ resolution simulation (henceforth SLD) using the set-up of Pollard and DeConto (2012), i.e. $n=2$. The resulting ice-sheet thickness distribution is very similar to that from the GR20 experiment, with a slightly smaller mean absolute error of $32.8 \mathrm{~m}$ (Table 2) due to reduced ice thickness underestimations near ice-sheet margins. Similarly, the estimated ice-shelf steady-state BMB of - $2074 \mathrm{Gt} \mathrm{a}^{-1}$ in the SLD simulation is slightly higher by absolute value, due to locally higher ice-stream velocities in certain areas such as those found upstream of the Crosson and Dotson ice shelves. The similarity between our SLD and GR20 experiments suggests that a calibration of basal sliding coefficients can be, in principle, applied to any smoothly varying relation between the basal shear stress and the sliding velocities (Pollard and DeConto, 2012).

Finally, our REF experiment uses a default value of $E_{\mathrm{SSA}}=$ 0.5 for the ice flow enhancement factor for ice shelves, which falls within the range of values commonly used in Antarctic ice sheet simulations (0.3-1.0, e.g. de Boer and others, 2015). The use of this value results in ice-shelf velocities that are locally underestimated compared with the observational dataset of Rignot and others (2011), as shown in Figure 2. Here, we test larger enhancement factors to assess their impacts on the modelled ice-shelf velocities and basal melt rates, including $E_{\mathrm{SSA}}=1, E_{\mathrm{SSA}}=2$ and $E_{\mathrm{SSA}}=3$ (Table 2). Compared with the REF experiment, the use of larger values of $E_{\mathrm{SSA}}$ increases the internal ice-shelf flow, thereby reducing the basal melt (particularly near grounding lines) needed to compensate for the accumulation in areas where the ice shelves receive a high ice flux from the grounded ice-sheet sectors. Furthermore, an increasingly faster ice-shelf flow in this series of simulations reduces the misfit between the modelled and observed ice-surface velocities, from $40 \mathrm{ma}^{-1}$ in the REF simulation, to $37 \mathrm{~m} \mathrm{a}^{-1}$ $\left(E_{\mathrm{SSA}}=1\right), 34 \mathrm{~m} \mathrm{a}^{-1}\left(E_{\mathrm{SSA}}=2\right)$ and $32 \mathrm{~m} \mathrm{a}^{-1} \quad\left(E_{\mathrm{SSA}}=3\right)$. Overall, the use of larger ice-shelf enhancement factors generates smaller total BMB estimates that are closer to those of Rignot and others (2013) and Depoorter and others (2013). Following the assumption that the ice flow enhancement factor for ice shelves should be $\leq 1$ (Ma and others, 2010), no special treatment of ice anisotropy in ice shelves $\left(E_{\mathrm{SSA}}=1\right)$ provides the best fit between our results and the cited studies. Since the same value is used across the grounded ice-sheet sectors $\left(E_{\mathrm{SIA}}=1\right.$, following the sensitivity analyses of Pollard and DeConto (2012) and Bernales and others (2017)), we have concluded that this tuning parameter can be excluded from our particular model set-up.

We have also performed a series of experiments testing the influence of other model parameters (Table 2), such as: (1) degree-day and lapse-rate correction factors in the surface mass-balance model, ranging from 3 to $15 \mathrm{~mm}$ i.e. day ${ }^{-1}{ }^{\circ} \mathrm{C}^{-1}$ for the former, and 6 to $10^{\circ} \mathrm{C} \mathrm{km}^{-1}$ for the latter, and (2) the parameters related to the iterative adjustment of the ice-shelf basal melting and freezing rates (Eqn (3)). For our particular model set-up driven by the presentday climate forcing, these experiments have not shown any significant sensitivity to the tested parameter variations.

\section{SUMMARY}

This study presents equilibrium estimates of basal melting and freezing rates for the entire Antarctic ice-shelf system derived from an ice sheet-shelf model and present-day observations of the ice-sheet geometry. Our method is a modelbased extension of the techniques presented in recent studies using the observed ice velocities and ice thickness to infer the ice-shelf BMB. In contrast, we derive the ice flow directly from an ice-sheet model calibrated against the ice-thickness observations and validated against the observed surface velocity field (Bernales and others, 2017). This approach allows for a detailed analysis of the BMB of ice shelves that are required by continental-scale, longterm ice-sheet models to reproduce the present-day geometry of the floating ice-sheet sectors. Our estimates complement previous glaciological and oceanographic reconstructions of the $\mathrm{BMB}$ of the Antarctic ice shelves.

The retrieved distribution of basal melting and freezing rates represents a total $\mathrm{BMB}$ steady-state estimate of $-1648.7 \mathrm{Gt} \mathrm{a}^{-1}$, that increases to $-1917.0 \mathrm{Gt} \mathrm{a}^{-1}$ when the observational ice-shelf thinning data from Pritchard and others (2012) are included. Our results exhibit similar patterns to those found by the observation-based study of Rignot and others (2013). In agreement with their reconstruction, we identify the highest ice-shelf basal melting rates near grounding lines and ice-shelf fronts, extensive accretion zones in-between under the biggest ice shelves, and high melting rates along the East Antarctic coasts suggesting that ocean thermal conditions there are similar to those detected in the Amundsen and Bellingshausen Sea sectors.

Additional experiments reveal that the use of a lower horizontal grid resolution tends to amplify the retrieved basal melting, thereby causing a significantly larger ice-mass loss from the Antarctic ice shelves. Since the misfit between our $\mathrm{BMB}$ estimates and those from the observational studies is reduced when an increasingly higher model resolution is employed, we anticipate that the use of even higher grid resolutions would further improve the agreement between the model-based estimates and the observational data.

Our estimates are insensitive to variations in the parameters controlling the iterative adjustment of the ice-shelf basal melting and freezing rates, and to changes in the degree-day and lapse-rate correction factors in the implemented surface mass-balance model. Similarly, variations in the basal sliding law and hybrid scheme formulation used to compute the grounded-ice velocities do not impose any significant changes in the predicted $B M B$ of ice shelves. A choice of a flow enhancement factor larger than our reference value of 0.5 decreases the estimated basal melt rates near grounding lines and the misfit between the observed and modelled ice-surface velocities of large ice shelves, showing that a value of $E_{\mathrm{SSA}}=1$ (i.e. no scaling of the ice-shelf flow) produces a total BMB estimate that is closer to the values obtained by Rignot and others (2013) and Depoorter and others (2013). Our experiments also show that uncertainties in the input datasets (topography, geothermal heat flux and climate forcing) hold the potential to strongly impact the retrieved ice-shelf basal melting and freezing rates by, for example, altering the ice flow patterns from the ice-sheet interior to its margins, and thus modifying the amount of ice mass that is routed towards the ice shelves across the grounding line.

Our model-based estimates reproduce well the complexity of the BMB of the Antarctic ice shelves, suggesting a strongly heterogeneous distribution of sub-shelf melting and freezing rates required by our model to fit the observed Antarctic ice-shelf geometry. Although these results cannot 
be directly implemented in freely evolving simulations with varying boundary conditions, they can be used as a firstorder approximation to guide the development of effective parameterisations of the ice/ocean interaction for largescale, long-term, prognostic modelling experiments.

\section{SUPPLEMENTARY MATERIAL}

The supplementary material for this article can be found at https://doi.org/10.1017/jog.2017.42.

\section{ACKNOWLEDGEMENTS}

We thank F. Pattyn and two anonymous referees for their very constructive comments that helped to improve this manuscript considerably. This work has been funded by the Helmholtz graduate research school GeoSim. IR was supported by the BMBF German Climate Modeling Initiative PalMod. We are very thankful to J.M. van Wessem for providing RACMO2.3 precipitation rate and near-surface temperature data and to J. Mouginot for providing the data necessary to reproduce their ice-shelf melting/freezing and thinning rates. All simulations were performed on the GFZ Linux Cluster GLIC.

\section{REFERENCES}

Agosta C, Fettweis X and Datta R (2015) Evaluation of the CMIP5 models in the aim of regional modelling of the Antarctic surface mass balance. Cryosphere, 9, 2311-2321 (doi: 10.5194/tc-9-2311-2015)

Beckmann A and Goosse H (2003) A parameterization of ice shelfocean interaction for climate models. Ocean Model. 5(2), 157170 (doi: 10.1016/S1463-5003(02)00019-7)

Bernales J, Rogozhina I, Greve R and Thomas M (2017) Comparison of hybrid schemes for the combination of shallow approximations in numerical simulations of the Antarctic Ice Sheet. Cryosphere, 11, 247-265 (doi: 10.5194/tc-11-247-2017)

Bindschadler RA and 27 others (2013) Ice-sheet model sensitivities to environmental forcing and their use in projecting future sea level (the SeaRISE project). J. Glaciol., 59(214), 195-224 (doi: 10.3189/2013JoG12J125)

Bueler E and Brown J (2009) Shallow shelf approximation as a "sliding law" in a thermomechanically coupled ice sheet model. J. Geophys. Res.: Earth Surf., 114(F3) (doi: 10.1029/ 2008JF001179)

Calov R and Greve R (2005) A semi-analytical solution for the positive degree-day model with stochastic temperature variations. J. Glaciol., 51(172), 173-175 (doi: 10.3189/1727565057 81829601)

Davis CH, Li Y, McConnell JR, Frey MM and Hanna E (2005) Snowfall-driven growth in East Antarctic ice sheet mitigates recent sea-level rise. Science, 308(5730), 1898-1901 (doi: 10.1126/science.1110662)

de Boer B and 12 others (2015) Simulating the Antarctic ice sheet in the late-pliocene warm period: PLISMIP-ANT, an ice-sheet model intercomparison project. Cryosphere, 9, 881-903 (doi: 10.5194/tc-9-881-2015)

Dee DP and 35 others (2011) The ERA-Interim reanalysis: configuration and performance of the data assimilation system. Quart. J. R. Meteorol. Soc., 137(656), 553-597 (doi: 10.1002/ qj.828)

Depoorter MA and 6 others (2013) Calving fluxes and basal melt rates of Antarctic ice shelves. Nature, 502(7469), 89-92 (doi: 10.1038/nature12567)

Doake CSM (1984) Antarctic mass balance: glaciological evidence from Antarctic Peninsula and Weddell Sea sector. In Glaciers Ice Sheets, and Sea Level: Effect of a CO2-induced Climatic
Change. Report of a Workshop Held in Seattle Washington September 13-15, 197-209

Dupont TK and Alley RB (2005) Assessment of the importance of iceshelf buttressing to ice-sheet flow. Geophys. Res. Lett., 32(4), L04503 (doi: 10.1029/2004GL022024)

Foldvik A, Gammelsrod T, Nygaard E and Osterhus S (2001) Current measurements near Ronne Ice Shelf: implications for circulation and melting. J. Geophys. Res.: Oceans, 106(C3), 4463-4477 (doi: 10.1029/2000JC000217)

Fox Maule C, Purucker ME, Olsen N and Mosegaard K (2005) Heat flux anomalies in Antarctica revealed by satellite magnetic data. Science, 309(5733), 464-467 (doi: 10.1126/ science.1106888)

Fretwell P and 55 others (2013) Bedmap2: improved ice bed, surface and thickness datasets for Antarctica. Cryosphere, 7, 375-393 (doi: 10.5194/tc-7-375-2013)

Gagliardini O and 14 others (2013) Capabilities and performance of Elmer/lce, a new-generation ice sheet model. Ceosci. Model Dev., 6, 1299-1318 (doi: 10.5194/gmd-6-1299-2013)

Gammelsrod T and 9 others (1994) Distribution of water masses on the continental shelf in the southern Weddell Sea. In OM Johannessen, RD Muench and JE Overland, eds, The polar oceans and their role in shaping the global environment, American Geophysical Union, Washington DC, 159-176 (doi: 10.1029/GM085p0159)

Gerdes R, Determann J and Grosfeld K (1999) Ocean circulation beneath Filchner-Ronne Ice Shelf from three-dimensional model results. J. Geophys. Res.: Oceans, 104(C7), 1582715842 (doi: 10.1029/1999JC900053)

Gillett NP, Arora VK, Zickfeld K, Marshall SJ and Merryfield WJ (2011) Ongoing climate change following a complete cessation of carbon dioxide emissions. Nat. Geosci., 4, 83-87 (doi: 10.1038/ngeo1047)

Greve R and Blatter H (2009) Dynamics of ice sheets and glaciers. Springer Science and Business Media, Berlin, Heidelberg.

Greve R and Blatter H (2016) Comparison of thermodynamics solvers in the polythermal ice sheet model SICOPOLIS. Polar Sci., 10(1), 11-23 (doi: 10.1016/j.polar.2015.12.004)

Gudmundsson GH (2013) Ice-shelf buttressing and the stability of marine ice sheets. Cryosphere, 7, 647-655 (doi: 10.5194/tc-7647-2013)

Hellmer HH (2004) Impact of Antarctic ice shelf basal melting on sea ice and deep ocean properties. Geophys. Res. Lett., 31(10) (doi: 10.1029/2004GL019506)

Hellmer HH, Kauker F, Timmermann R, Determann J and Rae J (2012) Twenty-first-century warming of a large Antarctic iceshelf cavity by a redirected coastal current. Nature, 485(7397), 225-228 (doi: 10.1038/nature11064)

Holland PR, Jenkins A and Holland DM (2008) The response of ice shelf basal melting to variations in ocean temperature. J. Clim., 21(11), 2558-2572 (doi: 10.1175/2007JCLI1909.1)

Holland PR, Corr HF, Vaughan DG, Jenkins A and Skvarca P (2009) Marine ice in Larsen ice shelf. Geophys. Res. Lett., 36(11) (doi: 10.1029/2009GL038162)

Holland PR, Jenkins A and Holland DM (2010) Ice and ocean processes in the Bellingshausen Sea, Antarctica. J. Geophys. Res.: Oceans, 115(C5) (doi: 10.1029/2008JC005219)

Hulbe C and Fahnestock M (2007) Century-scale discharge stagnation and reactivation of the Ross ice streams, West Antarctica. J. Geophys. Res., 112, F03S27 (doi: 10.1029/2006JF000603)

Hutter K (1983) Theoretical glaciology: material science of ice and the mechanics of glaciers and ice sheets, vol. 1. Springer, Dordrecht

Jacobs SS, Hellmer H, Doake CSM, Jenkins A and Frolich R (1992) Melting of ice shelves and the mass balance of Antarctica. J. Glaciol., 38(130), 375-387 (doi: 10.3198/1992JoG38-130375-387)

Jacobs SS, Jenkins A, Giulivi CF and Dutrieux P (2011) Stronger ocean circulation and increased melting under Pine Island Glacier ice shelf. Nat. Geosci., 4, 519-523 (doi: 10.1038/ngeo1188) 
Jenkins A and Holland DM (2002) A model study of ocean circulation beneath Filchner-Ronne Ice Shelf, Antarctica: implications for bottom water formation. Geophys. Res. Lett., 29(8), 34-31 (doi: 10.1029/2001GL014589)

Jenkins A and Jacobs S (2008) Circulation and melting beneath George VI ice shelf, Antarctica. J. Geophys. Res.: Oceans, 113 (C4) (doi: 10.1029/2007JC004449)

Joughin I and Padman L (2003) Melting and freezing beneath Filchner-Ronne Ice Shelf, Antarctica. Geophys. Res. Lett., 30(9) (doi: 10.1029/2003GL016941)

Joughin I, Alley RB and Holland DM (2012) Ice-sheet response to oceanic forcing. Science, 338(6111), 1172-1176 (doi: 10.1126/science.1226481)

Lenaerts JTM and 6 others (2012) Modeling drifting snow in Antarctica with a regional climate model: 1 . Methods and model evaluation. J. Geophys. Res., 117(D05108) (doi: 10.1029/2011JD016145)

Ma Y and 5 others (2010) Enhancement factors for grounded ice and ice shelves inferred from an anisotropic ice-flow model. J. Glaciol., 56(199), 805-812 (doi: 10.3189/0022143107 94457209)

Marsiat I (1994) Simulation of the northern hemisphere continental ice sheets over the last glacial-interglacial cycle: experiments with a latitude-longitude vertically integrated ice sheet model coupled to a zonally averaged climate model. Palaeoclimates, 1, 59-98

Martin MA and 6 others (2011) The potsdam parallel Ice sheet model (PISM-PIK)-part 2: dynamic equilibrium simulation of the Antarctic ice sheet. Cryosphere, 5, 727-740 (doi: 10.5194/tc-5727-2011)

Morland LW (1987) Unconfined ice-shelf flow. In CJ van der Veen and J Oerlemans, eds, Dynamics of the West Antarctic Ice Sheet Springer Netherlands, Dordrecht, 99-116

Padman L and 11 others (2012) Oceanic controls on the mass balance of Wilkins Ice Shelf, Antarctica. J. Geophys. Res.: Oceans, 117(C1) (doi: 10.1029/2011JC007301)

Pattyn F (2010) Antarctic subglacial conditions inferred from a hybrid ice sheet/ice stream model. Earth Planet. Sci. Lett., 295 (3), 451-461 (doi: 10.1016/j.epsl.2010.04.025)

Payne AJ and 5 others (2007) Numerical modeling of ocean-ice interactions under Pine Island Bay's ice shelf. J. Geophys. Res.: Oceans, 112(C10) (doi: 10.1029/2006JC003733)

Pollard D and DeConto RM (2012) A simple inverse method for the distribution of basal sliding coefficients under ice sheets, applied to Antarctica. Cryosphere, 6, 953-971 (doi: 10.5194/tc-6-9532012)

Pritchard HD and 5 others (2012) Antarctic ice-sheet loss driven by basal melting of ice. Nature, 484(7395), 502-505 (doi: 10.1038/ nature10968)
Reeh N (1991) Parameterization of melt rate and surface temperature in the Greenland ice sheet. Polarforschung, 59(3), 113-128

Rignot E and Jacobs SS (2002) Rapid bottom melting widespread near Antarctic ice sheet grounding lines. Science, 296(5575), 2020-2023 (doi: 10.1126/science.1070942)

Rignot E and 5 others (2004) Accelerated ice discharge from the Antarctic Peninsula following the collapse of Larsen B ice shelf. Geophys. Res. Lett., 31(18) (doi: 10.1029/2004GL020697)

Rignot E, Mouginot J and Scheuchl B (2011) Ice flow of the Antarctic ice sheet. Science, 333(6048), 1427-1430 (doi: 10.1126/ science.1208336)

Rignot E, Jacobs S, Mouginot J and Scheuchl B (2013) Ice-shelf melting around Antarctica. Science, 341(6143), 266-270 (doi: 10.1126/science.1235798)

Rott H, Müller F, Nagler T and Floricioiu D (2011) The imbalance of glaciers after disintegration of Larsen-B ice shelf, Antarctic Peninsula. Cryosphere, 5, 125-134 (doi: 10.5194/tc-5-125-2011)

Sato T and Greve R (2012) Sensitivity experiments for the Antarctic ice sheet with varied sub-ice-shelf melting rates. Ann. Glaciol., 53(60), 221-228 (doi: 10.3189/2012AoG60A042)

Schodlok MP, Menemenlis D, Rignot E and Studinger M (2012) Sensitivity of the ice-shelf/ocean system to the sub-ice-shelf cavity shape measured by NASA IceBridge in Pine Island Glacier, West Antarctica. Ann. Glaciol., 53(60), 156-162 (doi: 10.3189/2012AoG60A073)

Shepherd A and 46 others (2012) A reconciled estimate of ice-sheet mass balance. Science, 338(6111), 1183-1189 (doi: 10.1126/ science.1228102)

Snyder J (1987) Map projections - a working manual (USGS Professional Paper 1395). United States Government Printing Office, Washington, USA

Timmermann R, Wang Q and Hellmer HH (2012) Ice-shelf basal melting in a global finite-element sea-ice/ice-shelf/ocean model. Ann. Glaciol., 53(60), 303-314 (doi: 10.3189/ 2012AoG60A156)

van Wessem JM and 10 others (2014) Improved representation of East Antarctic surface mass balance in a regional atmospheric climate model. J. Glaciol., 60(222), 761-770 (doi: 10.3189/ 2014JoG14J051)

Wen J and 5 others (2010) Basal melting and freezing under the Amery Ice Shelf, East Antarctica. J. Glaciol., 56(195), 81-90 (doi: 10.3189/002214310791190820)

Winkelmann R and 6 others (2011) The potsdam parallel Ice sheet model (PISM-PIK)-part 1: model description. Cryosphere, 5, 715-726 (doi: 10.5194/tc-5-715-2011)

Yin J and 5 others (2011) Different magnitudes of projected subsurface ocean warming around Greenland and Antarctica. Nat. Geosci., 4, 524-528 (doi: 10.1038/ngeo1189) 